Review

\title{
Layered Double Hydroxide-Based Nanocarriers for Drug Delivery
}

\section{Xue Bi, Hui Zhang * and Liguang Dou}

State Key Laboratory of Chemical Resource Engineering, Beijing University of Chemical Technology, P.O. Box 98, Beijing 100029, China; E-Mails: leospindrift@126.com (X.B.); liguang0628@163.com (L.D.)

* Author to whom correspondence should be addressed; E-Mail: huizhang67@gst21.com; Tel.: +86-10-6442-5872; Fax: +86-10-6442-5385.

Received: 11 April 2014; in revised form: 15 May 2014 / Accepted: 20 May 2014 /

Published: 17 June 2014

\begin{abstract}
Biocompatible clay materials have attracted particular attention as the efficient drug delivery systems (DDS). In this article, we review developments in the use of layered double hydroxides (LDHs) for controlled drug release and delivery. We show how advances in the ability to synthesize intercalated structures have a significant influence on the development of new applications of these materials. We also show how modification and/or functionalization can lead to new biotechnological and biomedical applications. This review highlights the most recent progresses in research on LDH-based controlled drug delivery systems, focusing mainly on: (i) DDS with cardiovascular drugs as guests; (ii) DDS with anti-inflammatory drugs as guests; and (iii) DDS with anti-cancer drugs as guests. Finally, future prospects for LDH-based drug carriers are also discussed.
\end{abstract}

Keywords: layered double hydroxides; drug delivery system; controlled release; intercalation assembly; cardiovascular drug; anti-inflammatory drug; anti-cancer drug

\section{Introduction}

\subsection{Drug Delivery Systems (DDS)}

Drug delivery systems (DDS) are designed to either alter the pharmacokinetics and biodistribution of their associated drugs, or to function as drug reservoirs (i.e., as sustained release systems) —or 
both [1] — and should have the ability to enhance several crucial properties of "free" drugs, such as improving their solubility, in vivo stability and specificity, reducing or eliminating tissue damage, protecting the drug, or enhancing their efficacy [2]. Common organic-based DDS include polymers (such as chitosan [3], amphiphilic block copolymers [4], block copolymer micelles [5], hydrogels [6], cellulose [7], polysaccharides [8,9]), lipid particles (microemulsions [10]), and a few natural particulates (pathogens and mammalian) [11]. Organic-based DDS have some disadvantages such as high toxicity, low loadings and easy leakage of drugs which reduce their drug-delivering efficiency. Drug carriers based on inorganic nanomaterials, such as silica materials [12,13], show much better properties than organic carriers, including ease of controlled synthesis and environmental friendliness [14]. The recently developed organic-inorganic nanohybrids based DDS such as LDH-chitosan hybrid $[15,16]$ or enteric polymer [17] show good biocompatibility and avoid the drug leaching, but endure the difficulty of artificial synthesis, ordered structure, and industrial scale-up. Hence, the inorganic materials are much superior to the others on the synthesis and industrialization, the control of defined structure, and the avoidance of drug leakage as DDS in a long-term view. For inorganic materials, efficient administration with low bio-toxicity, facile synthesis, and easy storage with high stability are the most primary factors. The chemical and biological toxicity significantly rely on the choice of chemical elements and the control of particle size. Modification or functionalization by other inorganic or organic components may also create influence on the chemical and biological toxicity of inorganic materials. As for the fast transition of these nanomaterials for industrial scale up, design of assembly technology, data statistics and analysis upon the clinical tests, and long-term storage without loss of pharmacodynamic effect together with the economic evaluation are necessarily required but it is not easy to completely cover in one limited review. The present review mainly focuses on the synthetic strategy and release property in vitro. Some layered materials are excellent candidates for use in DDS since their lamellar structures provide a suitable interlayer spacing for drug molecules which can be incorporated, by a process such as ion-exchange [18]. In the case of natural smectite type clays, cationic species may be intercalated in the interlayer galleries, whereas in the case of layered double hydroxides (LDHs) - also known as hydrotalcite-like materials - anionic species may be intercalated. Although some LDHs occur naturally, recent years have seen an explosive growth in the controlled synthesis of new LDH materials and in this review we focus on the prospects of these synthetic LDHs for use in clinical therapy. It is worth mentioning that the pioneering works of Choy' group have led to a rapid development in the research on both varied LDHs/polymers/anions hybrid systems and pharmaceutical applications of LDHs especially involving the biocompatibility and toxicity of LDHs and anti-cancer drugs intercalated LDH materials.

All these positive attributes make drug-LDH nanocomposite an applicable platform in vivo for further evaluation. Drawing together the thoughts and methods from interdisciplinary fields, such as chemistry, biology, mathematics, etc., the drug-LDH materials present great potential in drug imaging or monitoring in human organs or tissues. Therefore, the research scope of this material is no longer limited to conventional studies about structural property and in vitro drug release property, but also expands to more subjects like biocompatibility, bio-distribution, or pharmacokinetics, which receive constant attention in clinical work. 


\subsection{Layered Double Hydroxide (LDH) Materials}

LDHs are a class of anionic lamellar compounds made up of positively charged brucite-like layers with an interlayer gallery containing charge compensating anions and water molecules. The metal cations occupy the centers of shared octahedra, whose vertices contain hydroxide ions that connect to form infinite two-dimensional sheets as shown in Figure 1. The most widely studied LDHs contain both divalent and trivalent metal cations and the generic formula for LDHs can be written as: $\left[\mathrm{M}^{2+}{ }_{1-x} \mathrm{M}^{3+}{ }_{x}(\mathrm{OH})_{2}\right]\left[\mathrm{A}^{n-}\right]_{x / n} \cdot z \mathrm{H}_{2} \mathrm{O}$, where $\mathrm{M}^{2+}$ may be cations such as $\mathrm{Mg}^{2+}, \mathrm{Zn}^{2+}$ or $\mathrm{Ni}^{2+}$, and $\mathrm{M}^{3+}$ may be cations such as $\mathrm{Al}^{3+}, \mathrm{Ga}^{3+}, \mathrm{Fe}^{3+}$ or $\mathrm{Mn}^{3+}, \mathrm{A}^{n-}$ is a non-framework charge compensating inorganic or organic anion, e.g., $\mathrm{CO}_{3}{ }^{2-}, \mathrm{NO}_{3}{ }^{-}, \mathrm{Cl}^{-}, \mathrm{SO}_{4}{ }^{2-}$, or $\mathrm{RCO}_{2}{ }^{-}$, and $x$ is the mole fraction of $\mathrm{M}^{3+}$ [19-24]. $\mathrm{M}^{+}$and $\mathrm{M}^{4+}$ cations can also be incorporated in the layers but examples are limited to specific cations such as $\mathrm{Li}^{+}$, $\mathrm{Ti}^{4+}$, and $\mathrm{Zr}^{4+}$. In the layers of $\mathrm{LDH}$ hosts, the $\mathrm{M}^{2+}$ and $\mathrm{M}^{3+}$ cations are not randomly distributed but ordered. For example, the solid state NMR studies by Grey et al. [25] showed that in MgAl-LDHs the cations are fully ordered for $\mathrm{Mg}^{2+} / \mathrm{Al}^{3+}$ ratios of 2:1 and a nonrandom distribution of the cations, without $\mathrm{Al}^{3+}-\mathrm{Al}^{3+}$ close contacts, persists for higher $\mathrm{Mg}^{2+} / \mathrm{Al}^{3+}$ ratios. The ordering of the cations affects the charge density of the LDH sheets, which has consequences for a variety of physicochemical parameters, such as the bonding, reactivity, orientation, and mobility of the chemical species in the interlayer gallery and on the surface.

Figure 1. Schematic representation of the structure of layered double hydroxides (LDHs).

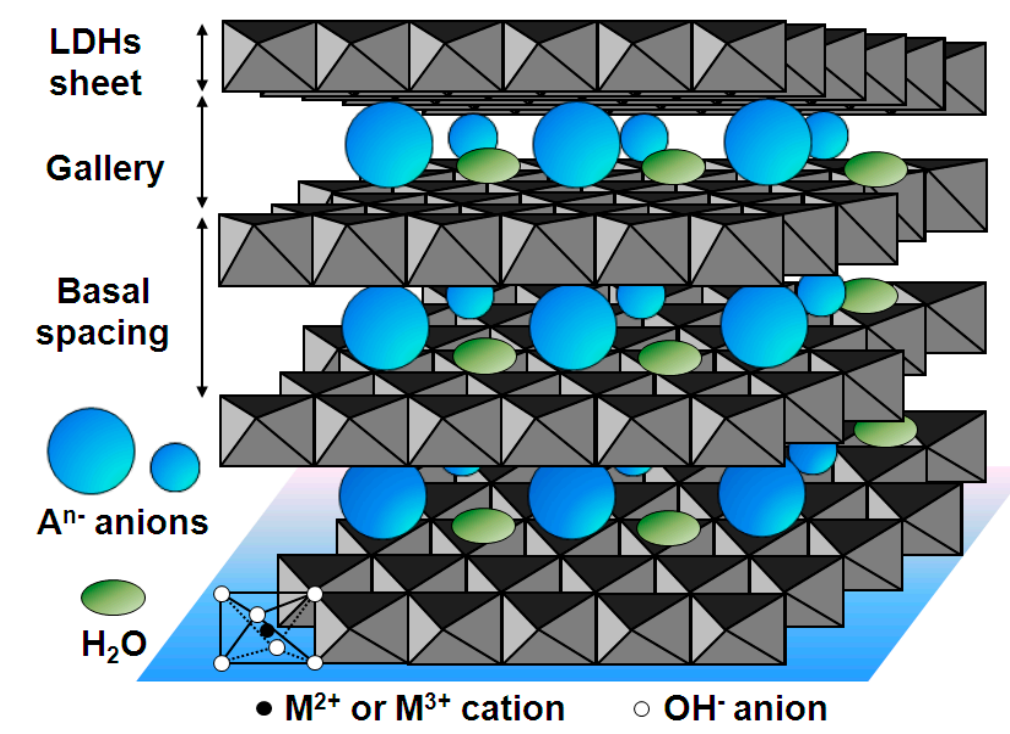

LDHs are not only easily synthesized, but also have several other attractive features such as the tunability of layer charge density and particle size, good biocompatibility, low toxicity, and a so-called "structural memory effect". Based on these properties, LDHs have been widely exploited to create new materials for applications in catalysis [26], drug delivery [27,28], and environmental remediation [29].

\subsection{LDH-Based Drug Carriers}

There are three main attractive features of LDH-based drug carriers: convenient synthesis, structural and morphological tunability, and their low toxicity and good biocompatibility. 


\subsubsection{Convenient Synthesis}

The synthesis of drug-LDH composite materials involves the assembly of organic ions/molecules in the interlayer galleries of the LDH host via electrostatic interactions or hydrogen bonds. O'Hare et al., have reviewed the systematic intercalation chemistry of LDH particles [20] and sheets [23] and highlighted how - in addition to the size of the guest species - the arrangement (monolayer or bilayer), size, and orientation of the guest as well as the interactions between the negatively charged guest and positively charged host are all critical factors in determining the separation between the layers. Several methods are commonly adopted for the synthesis of drug-LDH nanohybrids/nanocomposites, including the coprecipitation, ion-exchange, the calcination-reconstruction, hydrothermal, and exfoliation-restacking methods [17,21-23,28,30]. The coprecipitation method is most frequently used for the synthesis of drug-LDH nanohybrids since there is less risk of the incorporation of $\mathrm{CO}_{3}{ }^{2-}$ or other competing anions $[21,28]$. The ion-exchange method is also frequently used for the synthesis of drug-LDH nanohybrids $[21,30]$. LDH materials can also be formed by a calcination-rehydration (or reconstruction) method, in which the mixed metal oxides formed by calcination of an LDH precursor can be rehydrated in the presence of drug molecules to reform the LDH structure with the drug anions intercalated in the interlayer galleries [17]. Some neutral molecules may also be co-intercalated along with anions by this method. The hydrothermal method [24] is mainly used to improve crystallinity and uniformity of LDHs and may be less applicable in the case of drug-LDH nanohybrids if the drug has relatively low thermal stability. Although LDHs are harder to exfoliate than smectite clays because of their high layer charge density, several ways of achieving exfoliated LDHs have been developed in recent years and the restacking of the exfoliated nanosheets in the presence of drug species offers an attractive way of synthesizing drug-LDH nanohybrids under mild conditions, which is worthy of further exploration [23].

It should also be noted that the properties of drug-LDH nanohybrids/nanocomposites can be extended by incorporating a third functional component, such as organic [31-35], $\mathrm{SiO}_{2}[36,37]$, and $\mathrm{Fe}_{3} \mathrm{O}_{4}[38-40]$.

Some of the reaction routes to incorporate biomolecules into layered nanomaterials are summarized in Figure 2 [41]. For a specific drug-LDH composite, the choice of method is determined by a variety of factors such as the requirements on particle size, crystallinity, and loading amount of the drug. As it is shown in Figure 2, the inorganic sheets of a layered material such as an LDH act as a protective shield and their two-dimensional interlayer provide an ordered spacing which can effectively arrange the guest molecules. 
Figure 2. Reaction routes to incorporate biomolecules into layered nanomaterials (a) intercalation; (b) exfoliation-restacking; (c) pillaring reaction. Reprinted with permission from [41] (Copyright 2009 Royal Society of Chemistry).

(a)

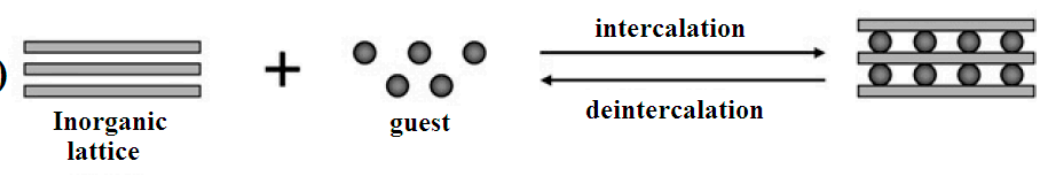

(b)

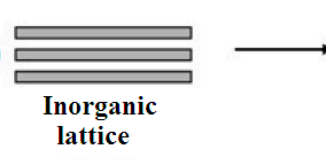

(c)

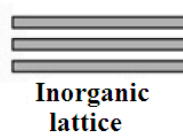

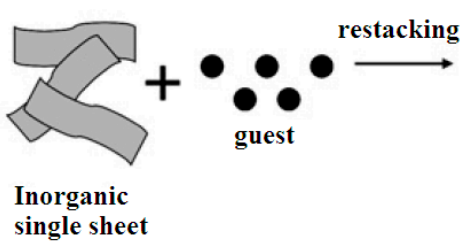

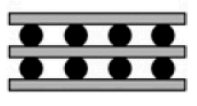
single sheet

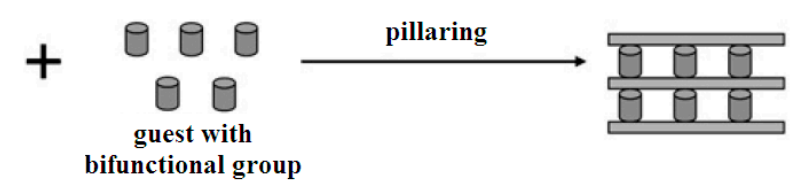

\subsubsection{Structural and Morphological Tunability}

The availability of LDH hosts with a wide range of chemical compositions allows materials with different structures and morphologies to be fabricated. For example, Duan et al. [30] showed that 5-aminosalicylate (5-ASA) intercalated ZnAl-LDH via direct coprecipitation and indirect ion-exchange methods with different $\mathrm{Zn}^{2+} / \mathrm{Al}^{3+}$ molar ratios had a variety of distinct arrangements of the 5-ASA guests in the interlayer galleries with various gallery heights.

Although the crystallites of LDH materials generally have a hexagonal plate-like morphology, the particle size can be readily controlled according to the demands of a specific application. For example, $\mathrm{Xu}$ et al. [42] fabricated $\mathrm{MgAl}-\mathrm{LDH}$ hollow nanospheres via direct assembly of preformed anisotropic LDH nanocrystals on the surface of carbon nanospheres followed calcinations and reconstruction to obtain ibuprofen (IBU)-intercalated LDH with $\sim 400 \mathrm{~nm}$ hollow nanosphere morphology. Zhang et al. [43] synthesized IBU-intercalated $\mathrm{MgAl}$ and $\mathrm{ZnAl}-\mathrm{LDH}$ nanohybrids by the coprecipitation followed hydrothermal treatment and found that the average plate-like particle sizes of the IBU-LDH nanohybrids can be tuned between 350 and $530 \mathrm{~nm}$ by modulating the aging time.

\subsubsection{Low Toxicity and Good Biocompatibility}

Many of the divalent and trivalent metal cations which can form LDHs have low toxicity. MgAl-LDHs are most frequently used as a LDH-based drug carrier and a significant number of studies have also been carried out with $\mathrm{ZnAl}-\mathrm{LDH}$. As evidence of its low toxicity, $\mathrm{MgAl}-\mathrm{LDH}-\mathrm{CO}_{3}$ is widely used as an antacid [44]. LDH hosts have the advantage that many different guest anions - including not only drugs, but also important agrochemicals, vitamins, fragrances, and dyes - can be intercalated without any degradation or loss of structural integrity of the guest, allowing the LDHs to act as a reservoir of the guest species [45]. Moreover, in addition to the intercalation of pharmaceutical drugs into layered materials causing no significant denaturation of the drug molecules, it has also been shown 
to enhance the internalization of the drug into a target cell without any noticeable side effects [41]. For example, 5-fluorouracil (5-Fu)-LDH exhibits favorable blood clearance profiles compared to free 5-Fu, such as sustained drug release, prolonged drug half-life, and increased drug accumulation in target tumor tissue [46]. Furthermore, LDH nanoparticles are rapidly excreted from the body and not accumulated in the organs after administration as 5-Fu-LDH, showing their efficacy as biodegradable particles for drug delivery [47]. Similarly, the greater inhibition of the cell cycle by methotrexate (MTX)-LDH compared with pure MTX has been demonstrated [48], and it was proposed that the internalization of LDH nanoparticles via clathrin-mediated endocytosis may allow the efficient delivery of MTX-LDH into cells and thus enhance drug efficiency.

Thus, LDHs can not only play a role as a biocompatible-delivery matrix for drugs but also afford a significant increase in the delivery efficiency [49-53]. However, before actual applications can be considered, the toxicity of drug-LDH composites in terms of damage to human tissue and organs must be studied. Choy et al. compared the toxicological effects of different nanoparticles focusing on their cytotoxicity and toxicity in vivo [51]. Choy et al. [52,53] further deduced that although LDH nanoparticles exhibit some cytotoxic effects, they are less toxic than other inorganic nanoparticles such as iron oxide, silica, and single walled carbon nanotubes at practical concentration levels. Although LDHs have low toxicity, high concentrations may still cause adverse effects [47]. Many toxicological studies of nanoparticles have demonstrated that the most important factor in determining the toxicity is the size of the particles themselves because they generally show size-dependent toxicity [54]. Examination of the size-dependent toxicity of LDHs in human lung cell cultures showed that $50 \mathrm{~nm}$ particles are more toxic than larger particles, while LDHs within the size range of 100-200 nm exhibits very low cytotoxicity in terms of cell proliferation, membrane damage, and inflammation response [55]. Besides particle size, the stability of an LDH also depends on the type of interlayer anions, and this can also affect the toxicity. It was reported [56] that $\mathrm{MgAl}-\mathrm{LDH}-\mathrm{Cl}$ dissolved more readily under simulated lysosomal $(\mathrm{pH} 4.5)$ and body fluid $(\mathrm{pH} 7.4)$ conditions than $\mathrm{MgAl}-\mathrm{LDH}-\mathrm{CO}_{3}$, and exhibited lower toxicity in terms of induction of oxidative stress, apoptosis and membrane damage.

\section{Drug-LDH DDS}

\subsection{Cardiovascular Drugs as Guests}

According to WHO (the World Health Organization), cardiovascular diseases rank first in the cause of death globally leading to strong demand for cardiovascular drugs with durable efficacy. To date, several cardiovascular drugs have been successfully integrated into LDH hosts for controlled drug delivery, indicating that LDHs are potential nanocarriers for the treatment of cardiovascular diseases.

As early as 2001, O'Hare et al. [57] reported the reversible intercalation of a number of active cardiovascular and anti-inflammatory agents into LDHs. As shown in Figure 3, at pH 4 the measured release of gemfibrozil is very fast with almost full deintercalation in less than $10 \mathrm{~min}$. While the release curve for gemfibrozil at $\mathrm{pH} 7$ is almost identical to the profile at $\mathrm{pH} 4$. These results show that the intercalation of pharmaceutically active compounds that can form stable anions is a feasible approach for the storage, and subsequent controlled release, of bioactive agents. 
Figure 3. Release profiles for (a) diclofenac at pH 4 and $\mathrm{pH} 7$ and (b) gemfibrozil at $\mathrm{pH} 4$ and pH 7. Reprinted with permission from [57] (Copyright 2001 Royal Society of Chemistry).
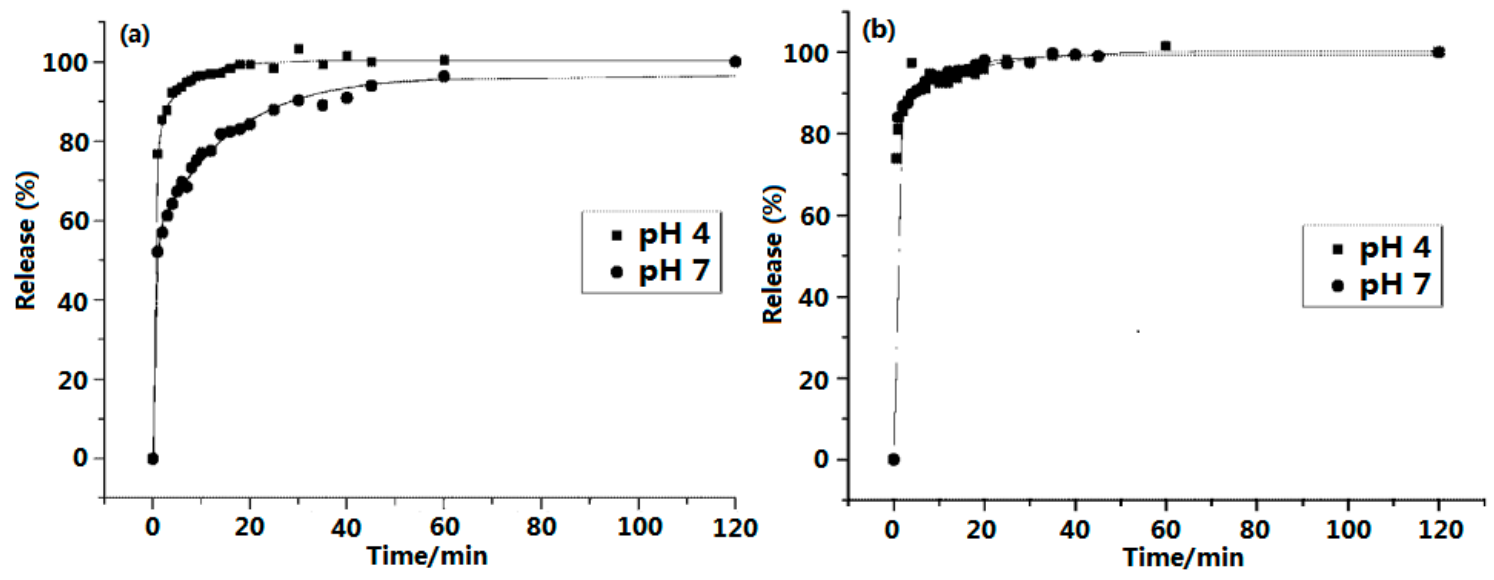

In 2006, Zhang et al. [58] developed a nanostructured drug-LDH composite involving a pharmaceutically active cardiovascular drug captopril $(\mathrm{Cpl})$ intercalated in an $\mathrm{Mg}_{2} \mathrm{Al}-\mathrm{LDH}$ host by a coprecipitation method. The interlayer spacing of the Cpl-LDH, evaluated by subtracting LDH layer thickness $0.48 \mathrm{~nm}$ from the interlayer distance $d_{003}$ (measured by powder X-ray diffraction (XRD)), is $0.982 \mathrm{~nm}$, which is larger than the molecular size of Cpl $(0.526 \mathrm{~nm})$ and this, together with Fourier transform infrared (FT-IR) and Raman spectroscopy data, suggest a vertical arrangement of a Cpl disulphide containing an S-S bond in interlayer gallery, with carboxylate anions interacting with both metal hydroxide layers. The proposed supramolecular structure of Cpl-LDH is presented in Figure 4.

Figure 4. Supramolecular structural model of Cpl-LDH. Reprinted with permission from [58] (Copyright 2006 Elsevier).

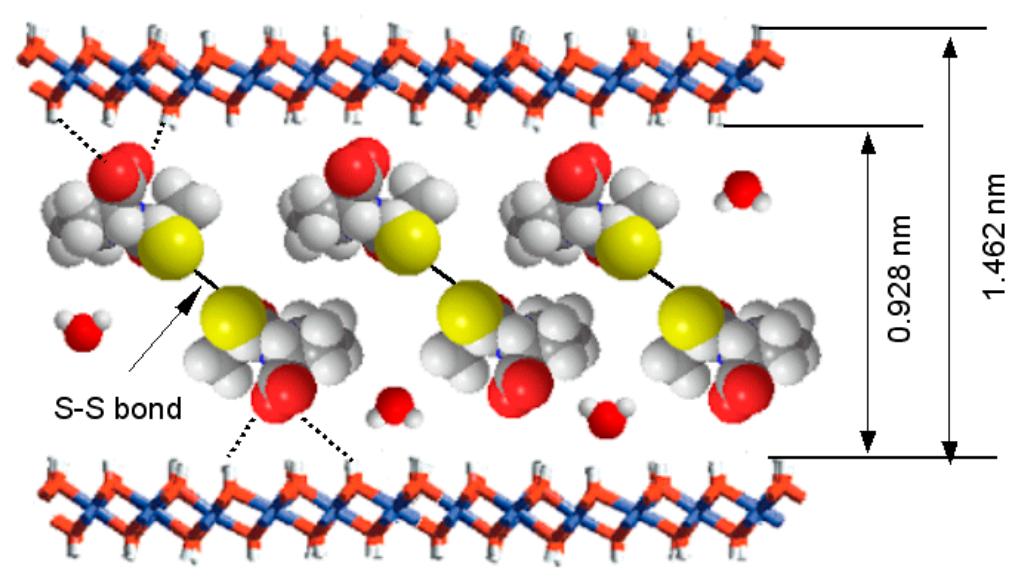

The in vitro release studies of Cpl-LDH in simulated gastrointestinal solutions at $37 \pm 1{ }^{\circ} \mathrm{C}$ (Figure 5) showed that at $\mathrm{pH} 4.60$, followed initial fast release, a slower release step is characterized by percentage releases of $c a .66 .7 \%, 85.1 \%$ and $94.2 \%$ after 1,10 and $140 \mathrm{~min}$, respectively, while at $\mathrm{pH} 7.45$, a slow and persistent process of $c a .12 .8 \%, 47.4 \%$ and $92.4 \%$ are obtained after 1,10 and $140 \mathrm{~min}$, respectively. It is worth noticing that no burst release phenomenon occurred in $\mathrm{pH} 7.45$ solution. Kinetic simulation of the release data and characterization results for samples recovered after 
release test indicate that a dissolution mechanism is mainly responsible for the release behavior of $\mathrm{Cpl-LDH}$ at $\mathrm{pH} 4.60$, while an ion-exchange mechanism for that at $\mathrm{pH}$ 7.45.

Low molecular weight heparin (LMWH) has also been intercalated into LDH hosts. In 2008, Gu et al. [59] prepared $\mathrm{Mg}_{2.4} \mathrm{Al}-\mathrm{LDH}-\mathrm{LMWH}$ hybrids with the desired $\mathrm{LMWH}$ loading $\left(\mathrm{LMWH}_{n}-\mathrm{LDH}\right.$, $n=10,20,50$, or 100 , where $n$ denotes the percentage of $\mathrm{Cl}^{-}$ions in pristine $\mathrm{Mg}_{2.4} \mathrm{Al}-\mathrm{LDH}-\mathrm{Cl}$ that are replaced by LMWH anions) using a similar coprecipitation method, aiming at overcoming the pharmaceutical limitations of heparin, namely, short half-life, low efficiency of cellular delivery, and lack of oral absorption. The in vitro release profiles in $\mathrm{pH} 7.4$ phosphate buffered saline (PBS) (Figure 6) show that LMWH20-LDH exhibits a gradual and biphasic release pattern, with an early fast release of LMWH (20.3\% of LMWH released after the first $12 \mathrm{~h}$ ) followed by a relatively slower release $(44.7 \%$ released after $120 \mathrm{~h}$ ), while LMWH100-LDH shows a similar biphasic release pattern, in which 23.3\% of LMWH was released in the first $12 \mathrm{~h}$ and $39.9 \%$ in $120 \mathrm{~h}$. The mechanism of release of LMWH from the LDH host probably involves surface diffusion and bulk diffusion via anionic exchange of LMWH anions on, or in, the LDHs with anions in the PBS solution.

Figure 5. Release profiles of $\mathrm{Cpl}$ from $\mathrm{Cpl-LDH}$ in buffer solutions at different $\mathrm{pH}$ values Reprinted with permission from [58] (Copyright 2006 Elsevier).

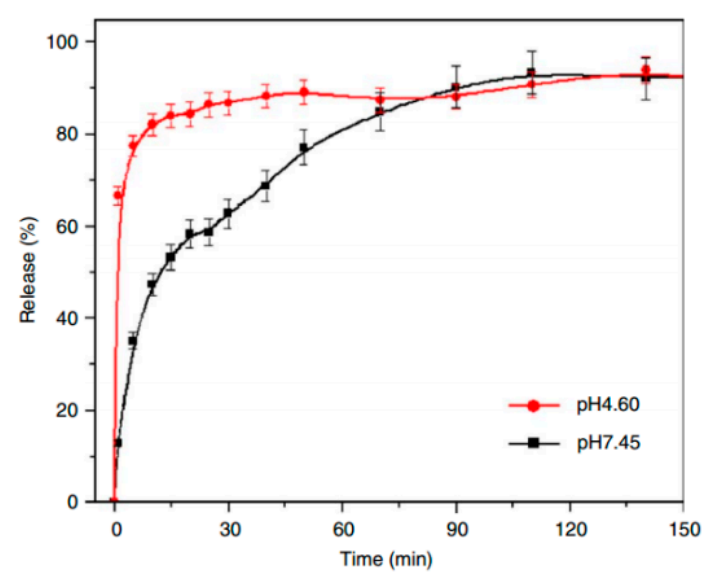

Figure 6. In vitro Low molecular weight heparin (LMWH) release curves from (a) LMWH20-LDH; (b) LMWH100-LDH; (c) physically mixed powder of heparin sodium salt and Cl-LDH (1/8 weight ratio). In (a) and (b), the solid and dashed curves represent the predictions of the modified Freundlich and parabolic diffusion model, respectively. Reprinted with permission from [59] (Copyright 2008 American Chemical Society).
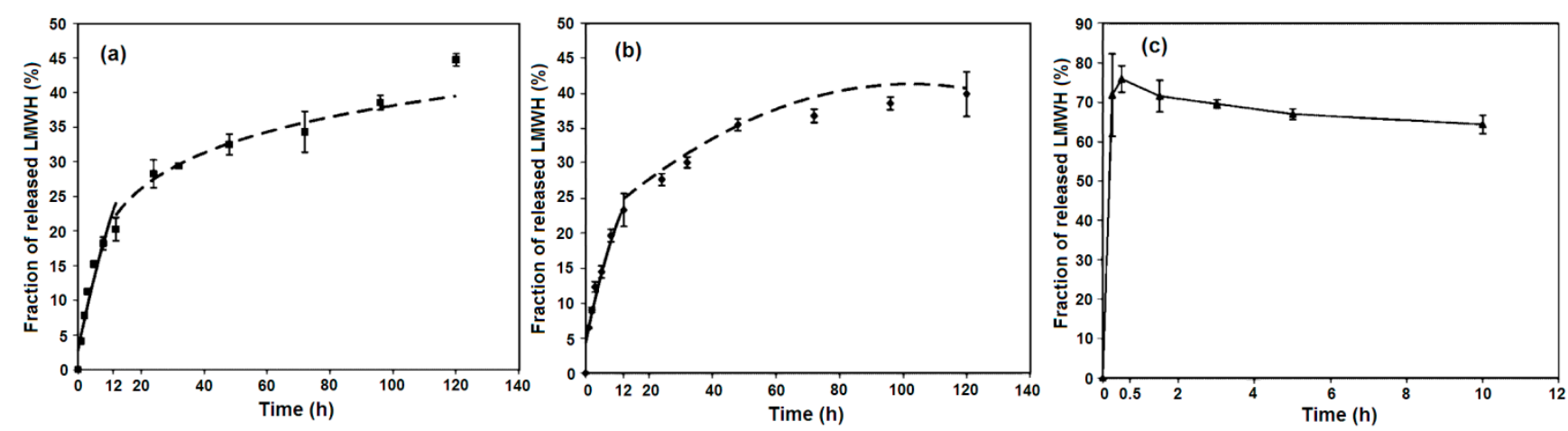
Pravastatin (prava) and fluvastatin (fluva) are members of the statin family of drugs that are highly effective for reducing cholesterol levels in the blood stream. In 2009, Panda et al. [60] reported the intercalation of pravastatin and fluvastatin drugs into $\mathrm{MgAl}-\mathrm{LDHs}$ via the coprecipitation technique. Characterization and computational results indicated that the fluvastatin anions are attached with the brucite as a hydrophobic monolayer, while the pravastatin anions form a hydrophilic multilayer. In vitro release study (Figure 7) indicated that although both the drugs contain single charged anions and the drug-LDH nanohybrids show a monophasic release pattern at $\mathrm{pH} 7.4$ as reported earlier for other drugs, MgAl-LDH-fluva exhibits a gradual and slow release pattern. In both cases, there is an early fast release (for pravastatin of $40 \%$ and fluvastatin of $20 \%$ ) of drug ions followed by a relatively slower release for fluvastatin. Also, on varying the concentration of hybrids materials in solution, there is a significant change in release patterns for both $\mathrm{MgAl}-\mathrm{LDH}-$ prava and MgAl-LDH-fluva hybrids. For MgAl-LDH-fluva, a concentration of $0.2 \mathrm{mg} \cdot \mathrm{mL}^{-1}$ gave $100 \%$ release in $16 \mathrm{~h}$, a concentration of $0.4 \mathrm{mg} \cdot \mathrm{mL}^{-1}$ gave $85 \%$ release in $32 \mathrm{~h}$ whilst a concentration of $0.55 \mathrm{mg} \cdot \mathrm{mL}^{-1}$ gave only $79 \%$ release in $52 \mathrm{~h}$; for $\mathrm{MgAl}-\mathrm{LDH}$-prava, a concentration of $0.2 \mathrm{mg} \cdot \mathrm{mL}^{-1}$ gave $100 \%$ release in $10 \mathrm{~h}$ and a concentration of $0.3 \mathrm{mg} \cdot \mathrm{mL}^{-1}$ gave $91 \%$ release in $10 \mathrm{~h}$. The great reduction in release rate of fluvastatin ions from MgAl-LDH-fluva upon materials concentration is ascribed to its hydrophobic nature, and this provides further means of controlling the rate of release in a physiological medium. The mechanism of drug diffusion in the hydrophobic MgAl-LDH-fluva nanohybrid probably involves heterogeneous diffusion via anion-exchange, while in the hydrophilic MgAl-LDH-prava nanohybrid it is due to intraparticle diffusion via anion-exchange with the anions in the physiological medium.

Figure 7. Release profile of statin drugs for (a) pravastatin and (b) fluvastatin based LDH systems under various physiological conditions. Reprinted with permission from [60] (Copyright 2009 American Chemical Society).
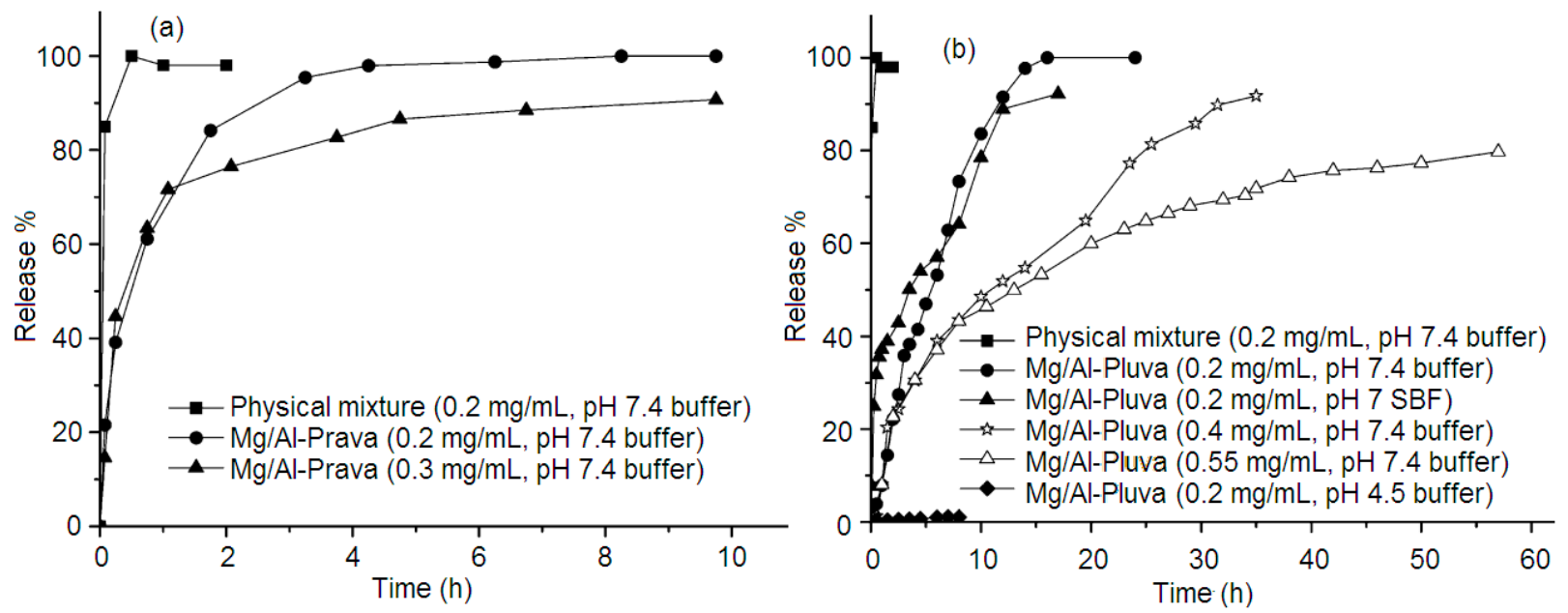

Fibrates such as bezafibrate (BZF) and clofibric acid (CF) are a class of lipid-regulating drugs that have been used in the treatment of many forms of hyperlipoproteinemia. In 2010, Berber et al. [61] used the coprecipitation method to intercalate BFZ and CF into an MgAl-LDH host; drug loadings of $54 \%$ and $45 \%$, respectively, were reached. The controlled release properties of BZF-LDH and $\mathrm{CF}-\mathrm{LDH}$ were attributed to the presence of anionic species in simulated gastrointestinal solutions. 
From the release data of $\mathrm{BZF}-\mathrm{LDH}$ and $\mathrm{CF}-\mathrm{LDH}$, the authors concluded that the nanocomposite formulation with LDHs facilitated the drug release properties.

\subsection{Anti-Inflammatory Drugs as Guests}

Non-steroidal anti-inflammatory drugs (NSAIDs) are aromatic organic compounds with easily ionizable carboxylic groups, thus permitting their intercalation as anions between the layers of LDH hosts [62]. It has been shown that many common NSAIDs, such as ibuprofen [42,43,63-68], naproxen [69-74], diclofenac [75-78], and some other drugs [30,79-84] can be rapidly intercalated in LDH hosts using a variety of methods, mainly coprecipitation, ion-exchange, and reconstruction.

Ibuprofen is a prototypical NSAID with analgesic and antipyretic properties and has been most widely selected as the guest. In 2001, Grandolini et al. [63] reported the intercalation of IBU in LDH-Cl via ion-exchange method. After intercalation of IBU, the interlayer distance of the host increased from $0.78 \mathrm{~nm}$ (parent $\mathrm{LDH}-\mathrm{Cl}$ ) to $2.17 \mathrm{~nm}$. The dissolution tests in simulated intestinal fluid buffer (PBS, pH 7.5) showed $60 \%$ of drug release at $20 \mathrm{~min}$ and $100 \%$ at $100 \mathrm{~min}$, quite different from those of physical mixture and commercial formulation Neo-Mindol ${ }^{\circledR}$. The mechanism of modified drug release was interpreted on the ion-exchange of the interlayer IBU anions with phosphate anions in PBS.

Subsequently, Silva et al. [64] reported the immobilization of ibuprofen on $\mathrm{Mg}_{3} \mathrm{Al}-\mathrm{LDH}$ by three routes compared with that of the $\mathrm{Cu}(\mathrm{II})$-ibuprofen salt by adsorption method. Evaluation of buffering properties showed that $\mathrm{Mg}_{3} \mathrm{Al}$-(ibuprofen) by the reconstruction method combines a significant amount (13\%) of immobilized ibuprofen with good buffering properties whilst the $\mathrm{Mg}_{3} \mathrm{Al}$-(ibuprofen) samples by ion-exchange and coprecipitation methods could be good carriers for the drug due to their higher ibuprofen loading ( $33 \%$ ) despite their poor buffering properties.

Three representative NSAIDs, ibuprofen, diclofenac, and indomethacin, were intercalated within the galleries of MgAl-LDHs via ion-exchange step by Vasudevan et al. [65]. The XRD patterns (Figure 8) showed that the (003) diffractions of precursor MgAl-LDH- $\mathrm{NO}_{3}$ disappear instead of those of drug-LDH hybrids at lower $2 \theta$ angles, indicating the completeness of the ion-exchange processes. The gallery height of $1.88 \mathrm{~nm}$ for MgAl-LDH-ibuprofen may be accounted for a bilayer arrangement with the carboxylate group of the ibuprofen anion (length $0.96 \mathrm{~nm}$ ) anchored to the hydroxide layer. Given that the dimensions and geometry of the diclofenac and indomethacin molecules are the same as in their crystalline state, the authors believed that the observed gallery heights 1.81 and $1.97 \mathrm{~nm}$ for MgAl-LDH-diclofenac and MgAl-LDH-indomethacin, respectively, implied partially interdigitated bilayers of the drug molecules arranged between the LDH layers. These hybrid materials have been identified as potential candidates for $\mathrm{pH}$-triggered drug release as well as drug storage.

In 2008, $\mathrm{Xu}$ et al. [66] reported the particles interactions-dependent control of drug release from $\mathrm{Mg}_{2} \mathrm{Al}$-LDHs intercalated with IBU through coprecipitation coupled with atmospheric aging or hydrothermal treatment in varied solvent. The sample obtained in ethylene glycol(EG)/water (volume ratio of 1:1) under hydrothermal condition forms c-oriented dense powder due to the preferential surface-to-surface and edge-to-edge aggregations of the large, regularly shaped and crystalline drug-LDH platelets. As a result, the release rate of IBU was considerably slower from the dense and oriented sample than that from loosely aggregated powders, due to the longer average diffusion path and higher diffusion resistance. These authors also demonstrated a simple method for 
generating LDH hollow nanospheres (Figure 9) via direct assembly of preformed anisotropic LDH nanocrystals (NCs) on the surface of carbon nanospheres [42]. The in vitro release study showed that there is no substantial difference in the release profiles between IBU-LDH hollow nanospheres and IBU-LDH nanoplates. However, the former has several advantages, such as (i) a lower density and less aggregation compared to the nanoplates, which leads to a better dispersion in the liquid phase for potential applications in controlled drug release with an intravenous injection mode; (ii) a higher surface area $\left(53.9 \mathrm{~m}^{2} \cdot \mathrm{g}^{-1}\right.$ compared to $14.7 \mathrm{~m}^{2} \cdot \mathrm{g}^{-1}$ for LDH nanoplates) allowing more effective surface modification by functional species (e.g., polymers or silica); and (iii) the interior space of the hollow nanospheres can be used for encapsulation of other molecules or nanoparticles (e.g., dyes or magnetic nanoparticles) to make multifunctional nanocomposites.

In 2011, Zhang et al. [43] fabricated MgAl-LDH nanohybrids intercalated with IBU through hydrothermal $(\mathrm{H})$ and coprecipitation $(\mathrm{C})$ methods in aqueous solution without any organic solvent. The (001) diffractions of the MA-IBU-H samples are obviously sharper than those of MA-IBU-C, indicating that the hydrothermal treatment leads to higher product crystallinity. The crystallinities and particle sizes of the MA-IBU-H- $i(i=18,36,72 \mathrm{~h})$ hybrids are greatly improved with increasing aging time indicated by the progressive decrease in the peak width of the (110) peak. The SEM (Figure 10) and TEM images show typical sheet-like morphology of all intercalates, with the platelet particles stacked and mostly adhering to one another. The average particle sizes of MA-IBU-H- $i$ nanohybrids are increased gradually from 350 to $530 \mathrm{~nm}$ with increasing aging time, and significantly larger than that of MA-IBU-C $(\sim 150 \mathrm{~nm})$. In vitro release studies for all the four intercalates in $\mathrm{pH} 7.45 \mathrm{PBS}$ indicated that the particle size has an important effect on the release rate and equilibrium. By quasi-in-time monitoring of the morphological changes of large-sized drug-LDH particles during the release process, it was found that the stacked and adhered platelet drug-LDH nanoparticles were gradually converted into isolated and thin plate-like LDH nanoparticles with curved edges.

Figure 8. X-ray diffraction patterns of (a) $\mathrm{MgAl}-\mathrm{LDH}-\mathrm{NO}_{3}$; (b) $\mathrm{MgAl}-\mathrm{LDH}-$ ibuprofen; (c) MgAl-LDH-diclofenac; and (d) MgAl-LDH-indomethacin. Reprinted with permission from [65] (Copyright 2005 American Chemical Society).

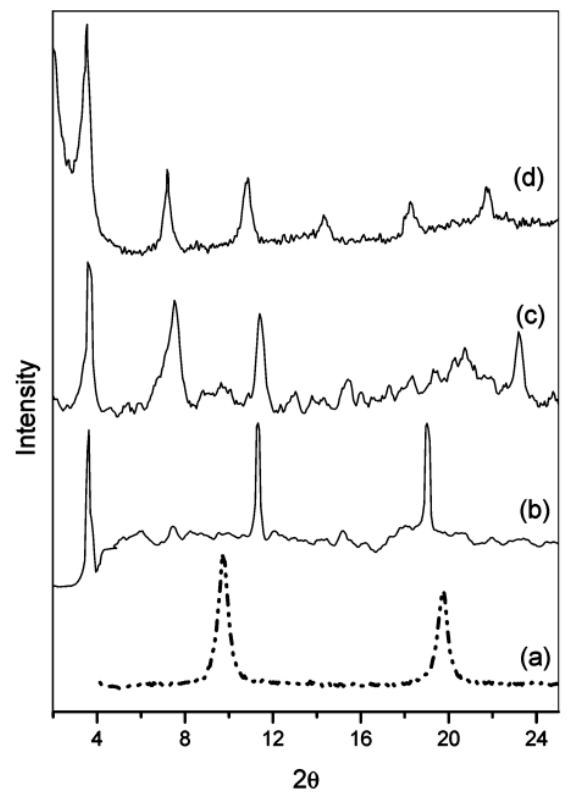


Figure 9. (Left) Scanning electron microscopy (SEM) (A) and transmission electron microscopy (TEM) (C) of metal oxide hollow nanospheres obtained after calcinations of LDH-NCs (nanocrystals)/central nervous system (CNS) composite and SEM (B) and TEM (D) of ibuprofen (IBU)-LDH hollow nanospheres after reconstruction; (Right) In vitro release profile of IBU from IBU-LDH hollow nanospheres in a buffer solution pH 7.0. The inset shows the release profiles from IBU-LDH nanoplates ( $\square$ ) and IBU sodium salt (A) under the same conditions. Modified with permission from [42] (Copyright 2009 American Chemical Society).
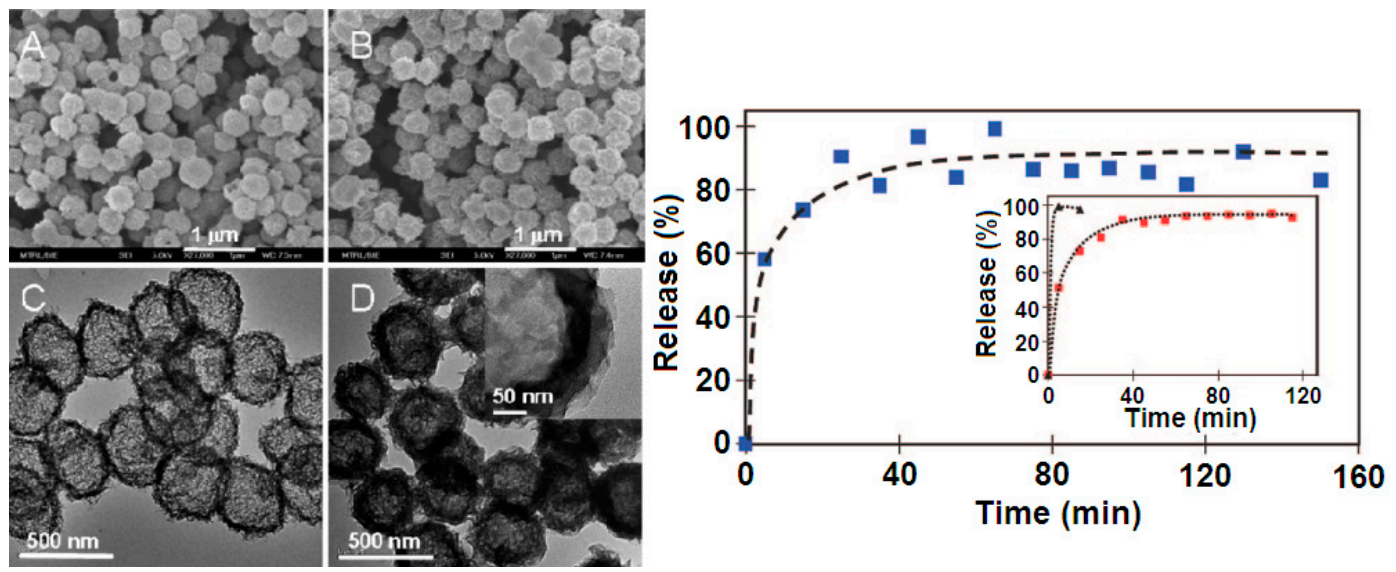

Figure 10. (Left) SEM images of MA-IBU-C (a) and MA-IBU-H- $i$ samples with $i=18 \mathrm{~h}$ (b), $36 \mathrm{~h}$ (c) and $72 \mathrm{~h} \mathrm{(d);} \mathrm{(Right)} \mathrm{Release} \mathrm{profiles} \mathrm{of} \mathrm{IBU} \mathrm{from} \mathrm{MA-IBU-C} \mathrm{(} \mathbf{a}$ ), MA-IBU-H-18 (), MA-IBU-H-36 ( $\Delta)$ and MA-IBU-H-72 $(\Delta)$ in pH 7.45 PBS. Modified with permission from [43] (Copyright 2010 American Institute of Chemical Engineers).
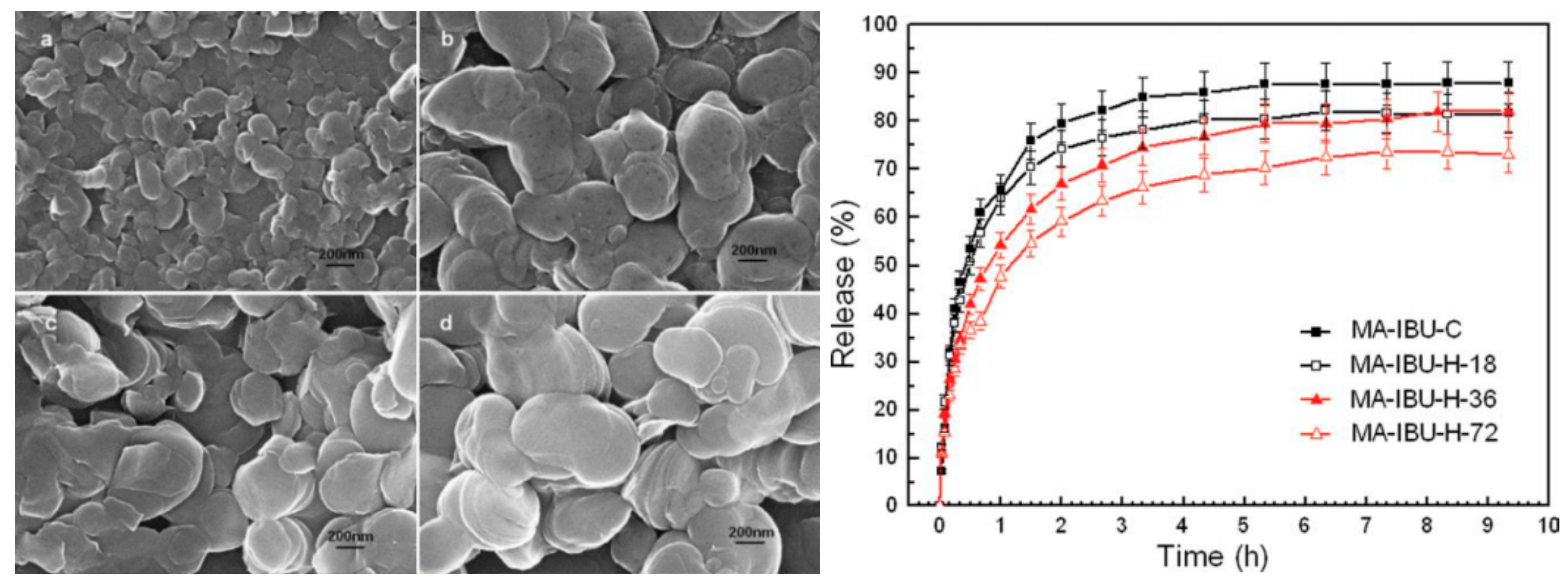

D'Souza and Golden [67] reported the intercalation of IBU in inorganic biodegradable polymer composites of LDH and poly-L-lactic acid (PLLA). The basal spacing expands from 0.89 to $2.48 \mathrm{~nm}$ (3\% IBU-LDH loaded) and $2.66 \mathrm{~nm}$ (5\% IBU-LDH loaded) with a titled double-layer arrangement of IBU within the gallery. Cumulative drug release was significantly improved by virtue of the novel nanocomposite architecture. Drug release studies showed a two-stage mechanism for release of the IBU from the nanocomposite films, but a single stage release from non-nano analogues. It was shown that the LDH works synergistically to strengthen PLLA while facilitating drug release. At shorter times periods $(<5 \mathrm{~h})$, the drug was released by diffusion, while ion-exchange predominates at longer time 
periods. These studies showed that ibuprofen could be intercalated into LDHs by an ion-exchange mechanism, maximizing therapeutic activity while minimizing toxic side effects.

Duan et al. [68] investigated the thermal decomposition process of naproxen-intercalated MgAl-LDHs by in situ FT-IR, in situ variable temperature XRD and thermogravimetry. It was found that the thermal stability of the intercalated naproxen was significantly enhanced compared with the pure form before intercalation, which suggests that this drug-inorganic layered material may have potential application as the basis of a novel drug storage system.

Berber et al. [69] reported the intercalation of naproxen in a MgAl-LDH by coprecipitation and studied the effect of the inorganic matrix on the drug solubility at $\mathrm{pH} 2$. The LDH dissolved in the acidic medium and the intercalated drug was released in a molecular form which is suitable for absorption. The solubility of the drug after intercalation was compared with that of the free drug. It was found that intercalation in the LDH host improves the drug solubility and its dissolution rate.

Rives et al. [70] have also studied the intercalation of naproxen in LDHs by both coprecipitation and anion-exchange with the $\mathrm{Al}^{3+}$ cations in the brucite layers partially substituted by $\mathrm{Fe}^{3+}$. In addition, the dissolution rate of the drugs was studied in vitro, in order to ascertain whether the LDH acts as a simple additive or as a matrix. The drug species, in their anionic form, were intercalated forming bilayers and during dissolution were exchanged with anions in the medium. This led to a slow release, much slower than when the LDH was simply and physically mixed with the drug, or when MgAl-LDH matrixes were used. These workers also reported the synthesis and characterization of materials where naproxen was incorporated in different inorganic matrices (MgAl-LDH, MCM-41 mesoporous silica and mesoporous alumina) [71], and the sustained release of the drug was compared using in vitro experiments. For the naproxen-LDH material, the amount of naproxen incorporated is much higher than for the mesoporous systems, as the drug molecules are located in the interlayers forming a bilayer to balancing the positive charge of the brucite-like layers.

Hou and Jin [72] reported the intercalation of naproxen into ZnAl-LDHs by the ion-exchange method involving the effects of varying the contact time, the composition, the layer charge density and the specific surface area of the LDHs, as well as the $\mathrm{pH}$ value on the uptake and release of naproxen by the LDHs. In the $\mathrm{pH}$ range of 6-11.5, the amount of naproxen uptaken by LDHs reduces with increasing $\mathrm{pH}$ values. The uptake by $\mathrm{LDH}-\mathrm{Cl}$ is much higher than that by $\mathrm{LDH}-\mathrm{CO}_{3}$ being probably due to the higher anion-exchange ability of the former. The naproxen molecules are possibly adsorbed on the surface of the basal layer of the LDH. In other words, a bilayer is formed in the interlayer gallery of the LDH host. They also found that the release rate of naproxen from the naproxen-LDH decreases with increasing charge density on the LDH layers and is much lower than that of a naproxen troche, implying an efficient drug-controlled release system of the naproxen-LDH nanohybrid.

Ricci et al. [73] prepared a microencapsulation of an $\mathrm{MgAl}-\mathrm{LDH}$ interaclated with diclofenac (HTlc-DIK) in order to obtain a composite system suitable for colonic drug delivery. Eudragit ${ }^{\mathbb{R}} \mathrm{S}$ or Eudragit $^{\circledR} \mathrm{L}$ were used as polymers for preparation of the microparticles (MPs) with two different HTlc-DIK/polymer ratios. DIK release from Eudragit ${ }^{\circledR}$ L MPs at $\mathrm{pH} 6.8$ reached 26\%-35\% within 25-30 min for the different HTlc-DIK/polymer ratios and no further increase was observed when the $\mathrm{pH}$ was increased to 7.5. DIK release from Eudragit ${ }^{\circledR} \mathrm{S}$ MPs at $\mathrm{pH} 7.5$ reached $70 \%$ after $6-8 \mathrm{~h}$ for both HTlc-DIK/polymer ratios. The results showed that LDH can be microencapsulated without loss of structural integrity and the resulting composite MPs showed good release property. Overall 
HTlc-DIK/Eudragit ${ }^{\circledR}$ S MPs possess superior features with respect to HTlc-DIK/Eudragit ${ }^{\circledR}$ L MPs suggesting that they could be promising systems for drug delivery either to the distal part of the small intestine or to the colon.

Cipiciani et al. [74] selected a $\left[\mathrm{Zn}_{0.72} \mathrm{Al}_{0.28}(\mathrm{OH})_{2}\right] \mathrm{Br}_{0.28} \cdot 0.69 \mathrm{H}_{2} \mathrm{O} \mathrm{LDH}$ as the host of the anionic to form diclofenac-LDH by ion-exchange method. The drug release profiles at different $\mathrm{pH}$ and in different media (Figure 11) showed that the drug release was complete in phosphate buffer at $\mathrm{pH} 7.5$ but incomplete in $\mathrm{pH} 7.0$ phosphate and $\mathrm{pH} 7.0 \mathrm{Na}_{2} \mathrm{HPO}_{4} / \mathrm{NaCl} / \mathrm{Na}_{2} \mathrm{CO}_{3}$ buffers, suggesting that the rate of release is more sensitive to acidic $\mathrm{H}_{2} \mathrm{PO}_{4}{ }^{-}$ions than to $\mathrm{CO}_{3}{ }^{2-}$ or $\mathrm{Cl}^{-}$ions.

Figure 11. Release curves of DIK from ZnAl-LDH-DIK under different conditions. Reprinted with permission from [74] (Copyright 2011 Elsevier).

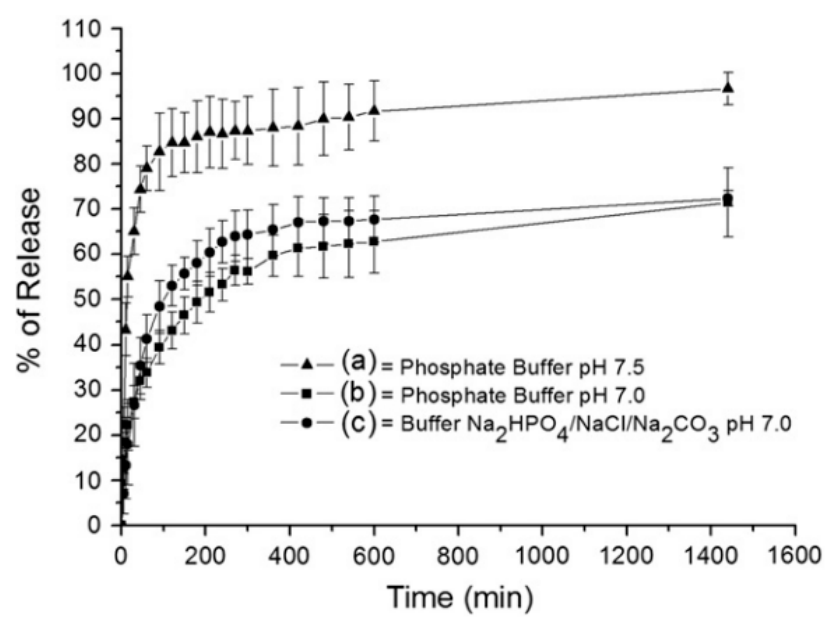

Rives et al. [75] also studied the intercalation of diclofenac, chloramphenicol, and ketoprofen into ZnAl, MgAl, ZnMgAl-LDH by coprecipitation method. The resulting nanohybrids show a relatively high crystallinity with drug molecules interacting strongly with the brucite-like layers. They also [76] attempted to modify the controlled release characteristics by incorporating the drug-LDHs into the biodegradable polymer PLLA and found that the release rate of drug was dramatically reduced and was not complete even after 3 months for any of the samples. Only 36\% of ketoprofen was released from the drug-LDH-PLLA system after three months, while the amounts released in the cases of diclofenac and chloramphenicol were $24 \%$ and $70 \%$, respectively. They pointed out that nevertheless, the net amounts of drug released might be therapeutically appropriated in all cases, as the amount of drug reaching the tissue would be of the same order as that obtained by oral dosing and the presented release pathway might be also beneficial for the interaction between the drug and the tissue.

About other anti-inflammatory drugs, Duan et al. [77] reported the intercalation of the fenbufen into LDHs by coprecipitation route associated with intercalation conditions such as $\mathrm{pH}$ value of the solution and chemical composition of the host. The interlayer distance in the intercalated materials increased with increasing $\mathrm{pH}$ value, resulting from a change in the arrangement of interlayer anions from monolayer to interdigitated bilayer. Drug release characteristics of the pillared LDH materials were investigated by a dissolution test in a simulated intestinal fluid ( $\mathrm{pH} 7.8$ ). The results showed that the release of the drug from the supramolecular LDH materials is a slow process, especially in the case of $\mathrm{Mg} / \mathrm{Al}$ intercalated materials, suggesting that these drug-inorganic hybrids can be used as an effective 
drug delivery system. They subsequently prepared a core-shell material [78] using fenbufen-LDH as the core coated with enteric polymers, Eudragit ${ }^{\circledR}$ S 100 or Eudragit ${ }^{\circledR}$ L 100 as a shell, giving a composite with controlled drug release behavior under in vitro simulated gastrointestinal tract conditions.

Rives et al. [79] also studied the intercalation of fenbufen into $\mathrm{LDHs}$ containing $\mathrm{Mg}^{2+}$ and $\mathrm{Al}^{3+}$ or $\mathrm{Mg}^{2+}, \mathrm{Al}^{3+}$ and $\mathrm{Fe}^{3+}$ cations by reconstruction route, with interlayer spacings ranging between 1.61 and $1.88 \mathrm{~nm}$. The presence of the LDH increases the s the drug is olubility of fenbufen, especially when used as a matrix. The dissolution rate of the drug decreases when intercalated, and is even lower in those systems containing iron; release takes place through ion-exchange with phosphate anions in the solution. Preparation of microspheres with Eudragit ${ }^{\circledR}$ S 100 afforded solids with a homogeneous, smooth surface with efficient covering of the LDH surface, as drug release was not observed at $\mathrm{pH}$ lower than 7, showing that the Eudragit ${ }^{\circledR}$ S 100 acts as an effective enteric coating for drug-LDH.

Another NSAID flurbiprofen (FLUR), belonging to class II of the Biopharmaceutical Classification System (BCS), was intercalated into LDHs by Perioli et al. [80] in order to evaluate the effect of the intercalation on the drug dissolution rate in an acid medium, the FLUR gastric permeability in the presence of MgAl-LDHs, and the in vitro FLUR release profile in an intestinal environment. It was found that the lamellar structure of LDHs quickly dissolves releasing the drug in a molecular form in acidic conditions; the co-administration of MgAl-LDH ensures not only an antacid effect but also affords an improvement in drug permeation through the gastric mucus which would probably lead to a better drug absorption in vivo. Choy et al. [81] also reported the intercalation of FLUR into LDH via a coprecipitation step. They showed that the nanohybrids can release the drug in a sustained manner, which can be better controlled with the presence of a macromolecule with comparable polarity to the incorporated drug. Upon the in vitro release results, the drug release could be facilitated by the presence of an anionic macromolecule, Eudragit ${ }^{\circledR}$ S 100, in the release medium.

5-Aminosalicylate, widely used in the treatment of inflammatory bowel disease, including ulcerative colitis and Crohn's disease, was intercalated into $\mathrm{Zn}_{R} \mathrm{Al}-\mathrm{LDH}$ ( $R$ is $\mathrm{Zn} / \mathrm{Al}$ molar ratio) by Duan et al. [30] through both direct coprecipitation (CP) and indirect ion-exchange (EX) methods. It was found that the EX products possess more ordered crystallites than the $\mathrm{CP}$ ones and the intercalates with higher layer charge density, i.e., lower $\mathrm{Zn} / \mathrm{Al}$ ratio, and exhibit more ordered crystal structures and higher thermal stability than those with lower layer charge densities. For EX intercalates, when the available area per monovalent anion is smaller than the cross section of the 5-aminosalicylate ion $\left(\mathrm{ASA}^{-}\right)$, the interlayer $\mathrm{ASA}^{-}$ions adopt a staggered interpenetrating arrangement, whereas when the available area is sufficiently large, the $\mathrm{ASA}^{-}$ions adopt the vertical neighboring monolayer arrangement. For CP intercalates, when the available area per monovalent anion is smaller than the cross section of the $\mathrm{ASA}^{-}$ion, the interlayer $\mathrm{ASA}^{-}$ions adopt a vertically distant bilayer arrangement, whereas when the available area is sufficiently large the $\mathrm{ASA}^{-}$ions adopt a vertical neighboring bilayer arrangement.

Indomethacin was intercalated into $\mathrm{Mg}_{2} \mathrm{Al}-\mathrm{LDHs}$ by Rives et al. [82] through calcinations-reconstruction and coprecipitation routes. The coprecipitation sample shows a single layered structure while the reconstruction sample with contamination of another layered $\mathrm{MgAl}-\mathrm{CO}_{3}$ phase and the amount of drug intercalated, as well as the height of the gallery, is larger for the former. Pharmacological studies in vivo showed that intercalation of the drug in the LDH host reduced the ulcerating damage of the drug. The same group also reported the intercalation of mefenamic and meclofenamic acid anions in 
$\mathrm{Mg}_{2} \mathrm{Al}$-LDHs by coprecipitation, ion-exchange and reconstruction methods [83]. Intercalation was achieved using all three methods, with the gallery height ranging between 1.65 and $1.75 \mathrm{~nm}$ depending on the particular drying conditions; these values suggested that the organic molecules form bilayers in the interlayer space.

A dexamethasone (Dexa) sodium phosphate was intercalated into MgAl-LDHs by Bahadur et al. [84] using the coprecipitation technique. An in vitro release study of the nanohybrid particles showed a significant reduction in release rate of dexamethasone phosphate anions from MgAl-LDH-Dexa after confinement of the drug anions in the LDH interlayer gallery. The mechanism of drug diffusion in the nanohybrid was studied using the dissolution-diffusion kinetic model, and it was found that it is probably due to dissolution and intraparticle diffusion of anions in the physiological medium.

\subsection{Anti-Cancer Drug as Guests}

As a disease with high mortality and few effective therapies, cancer is an international problem within the medical profession. Riaz and Ashaf [85] have given a short review of recent research into the intercalation and delivery of anti-cancer drugs using LDHs. To date, LDHs have been utilized as nanocarriers for many anti-cancer drugs, such as folinic acid [48], methotrexate [48,50,86-93], 5-flourouracil [94-97] and doxifluridine [17], comptothecin [98-100], $\mathrm{K}_{7}\left[\mathrm{PTiW}_{10} \mathrm{O}_{40}\right] \cdot 6 \mathrm{H}_{2} \mathrm{O}$ [101], podophyllotoxin [102], and doxorubicin [103].

Methotrexate (MTX), a folic acid antagonist commonly used to treat cancer sufferers, but with very short plasma half-life, leads to administering a high dose that can cause drug resistance and nonspecific toxicities in normal proliferating cells and therefore needs to be modified by organic or inorganic nanoparticles. About the modification of MTX by LDH, Choy et al. made significant contributions [48]. Early in 2004, Choy et al. [48] prepared MTX-MgAl-LDH hybrid via ion-exchange method from $\mathrm{Mg}_{2} \mathrm{Al}-\mathrm{NO}_{3}$ precursor. In vitro bioassay (Figure 12) showed that during the initial period, MTX-LDH is more efficient than MTX in suppression of the proliferation of tumor cell (fibroblast (human tendon) and SaOS-2 (Osteosarcoma, human)), and the clear difference in drug efficiency between MTX-LDH and MTX lasts for three days after administration. This result indicated that delivery to tumor cells is noticeably enhanced by hybridization with LDH and in this system MTX can reach the tumor cell membrane without any early decomposition due to stabilization and protection from the LDH host.

In the follow-on work, Choy et al. [50] obtained a similar MTX-LDH via a coprecipitation step and found that in an osteosarcoma cell culture line, the clathrin-mediated endocytosis of LDH nanoparticles also enhances the internalization of conjugated MTX molecules, and the MTX-LDH was more toxic to cancer cells than MTX alone due to the more effective penetration through the cell membrane (Figure 13). The anti-cancer efficiency of this MTX-LDH material was also investigated by in vitro bioassays such as 3-(4,5-dimethylthiazol-2-yl)-2,5-diphenyltetrazolium bromide (MTT) and BrdU (5-bromo-2-deoxyuridine) with the bone cancer cell culture lines (Sao-2 and MG-63) [86]. It was also found that the LDH host itself had no adverse effects on both normal and cancer cells up to a concentration of $500 \mu \mathrm{g} \cdot \mathrm{mL}^{-1}$.

Thereafter, Choy et al. [87,88] further reported the structure of anti-cancer drug-LDH nanohybrid MTX-LDH and its cellular interaction with human breast adenocarcinoma MCF-7 cells and drug resistance upon enhanced permeability and retention effect of MTX-LDH nanoparticles. 
Figure 12. The effect of methotrexate MTX-LDH on normal (Left) and tumor (Right) cell growth at the concentration of $5.0 \mu \mathrm{g} \cdot \mathrm{mL}^{-1}$. Reprinted with permission from [48] (Copyright 2004 Elsevier).
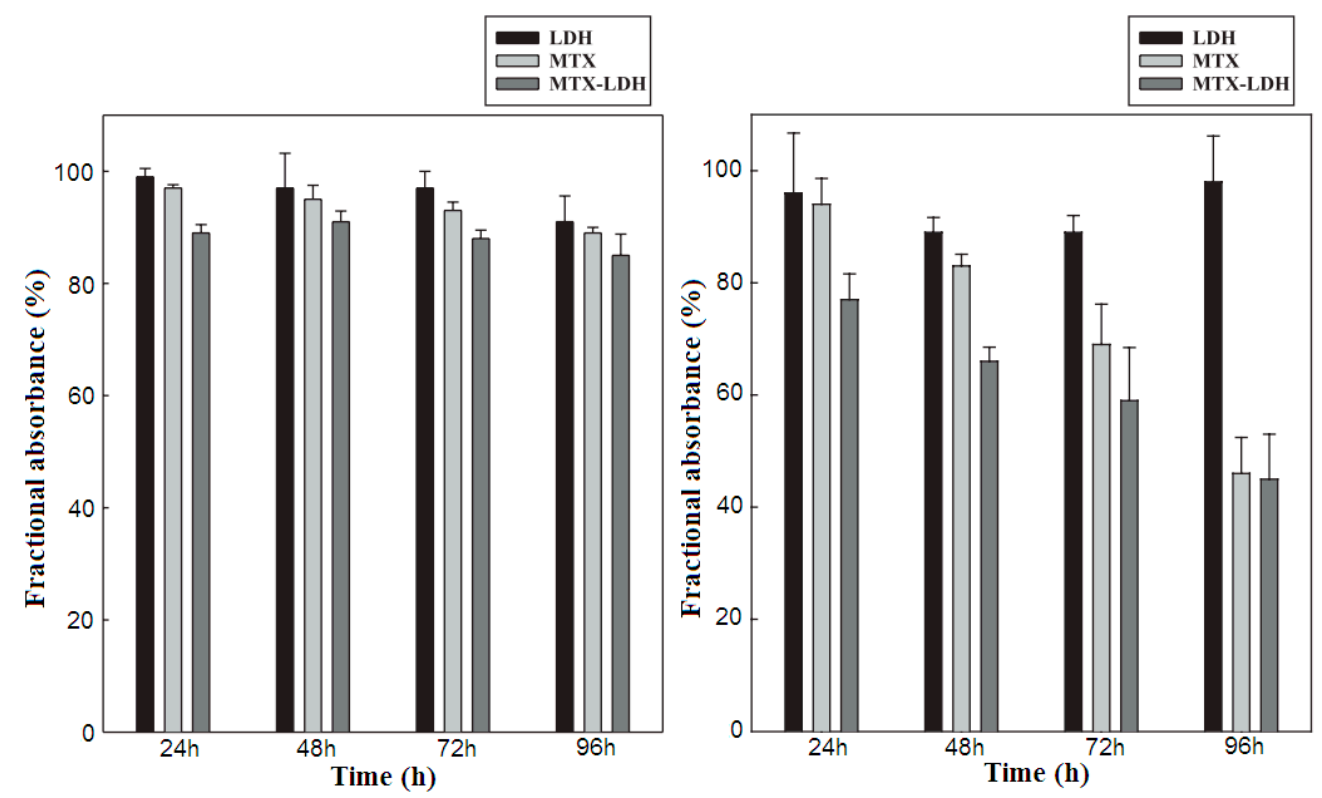

Figure 13. Cellular accumulation of free MTX molecules in MNNG/HOS cells treated with either MTX (०) or MTX-LDH (•). (A) Cell viability/cytotoxicity of MNNG/HOS cells treated with LDHs $(\boldsymbol{\Delta})$, MTX $(\circ)$, and MTX-LDH $(\bullet)$, as monitored by trypan blue exclusion, with respect to drug concentration (B). Reprinted with permission from [50] (Copyright 2006 American Chemical Society).
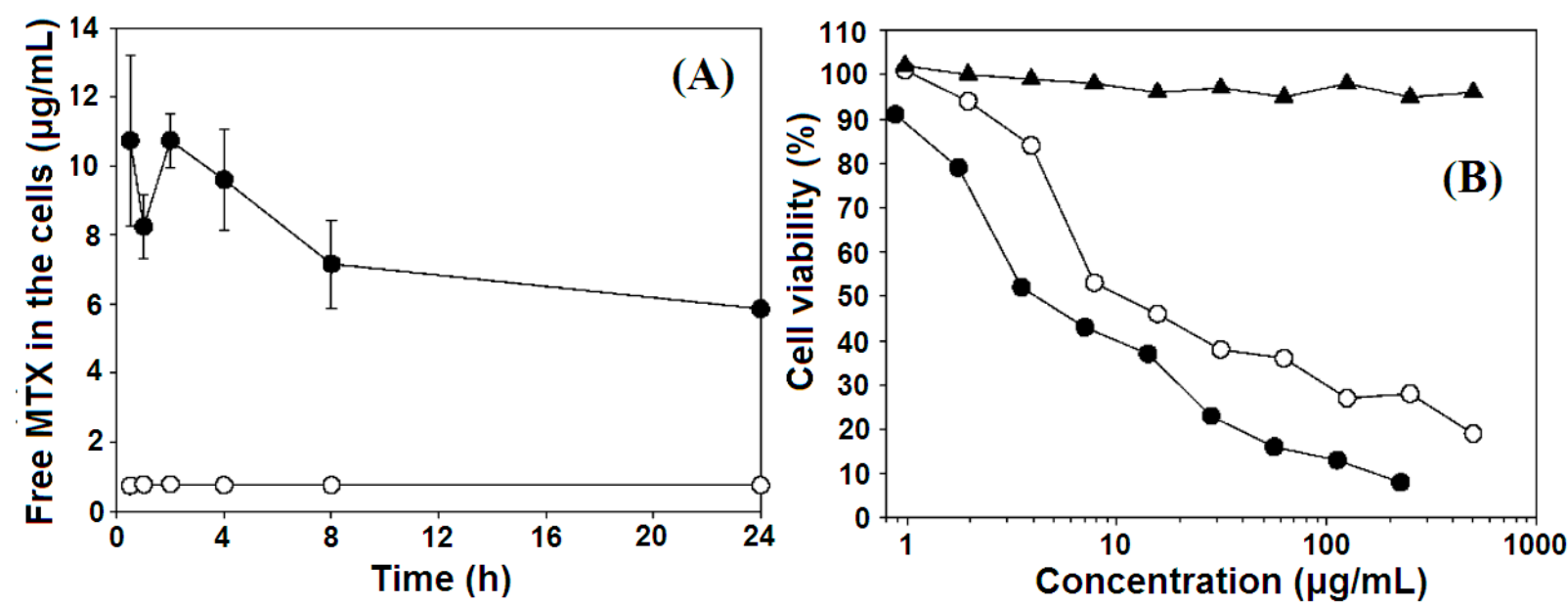

In the meantime, Chakraborty and Ghosh [88-92] also prepared MTX-LDH by different methods and studied the particle dissolution and subsequent drug release properties from the matrix in PBS solution. A striking enhancement in efficacy/sensitivity of MTX against HCT-116 cells was obtained when intercalated within the LDH host, as revealed by the attainment of the half maximal inhibitory concentration of MTX-LDH nanohybrid after only $48 \mathrm{~h}$, whereas bare MTX required $72 \mathrm{~h}$ to achieve the same effect. The MTX release from MgAl-LDH-MTX hybrids in PBS at pH 7.4 followed 
relatively slow first order kinetics (Figure 14) and was complete within 8 days following diffusion and crystal dissolution mechanisms.

Figure 14. (a) Cumulative release of MTX from MgAl-LDH-MTX matrix as a function of time and (b) the release data fitted to the first order kinetics model. Reprinted with permission from [92] (Copyright 2013 Elsevier).
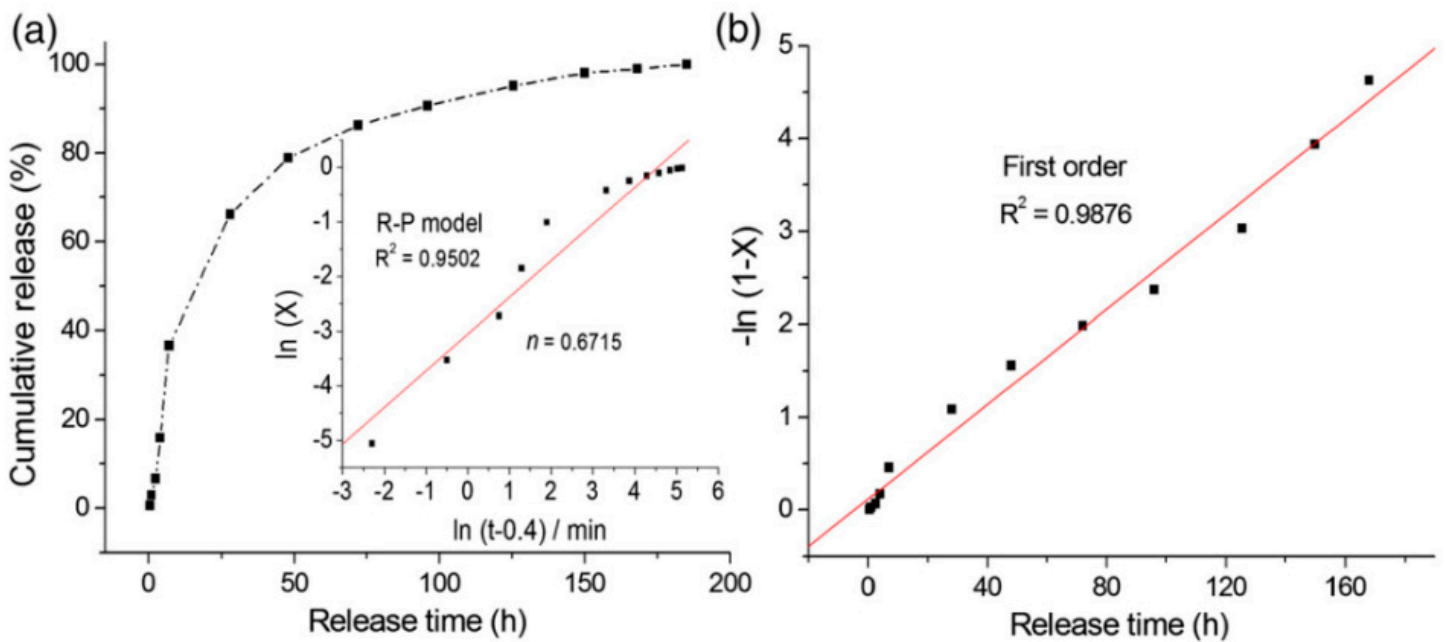

Chen et al. [93] developed a novel carrier for MTX by modifying an LDH host with folic acid (FA) molecules which had been covalently attached to (3-aminopropyl) triethoxysilane (APTES). The loading of MTX is $27.4 \mathrm{wt} \%$. The FA-conjugated LDH nanoparticles greatly improve the efficiency of MTX and perform much better in killing cancer cells in comparison with free MTX.

5-Fluorouracil $(5-\mathrm{Fu})$ is a neutral weak acid and anti-metabolic drug which is used extensively in cancer chemotherapy although it also has adverse effects on the human body. Wang et al. [94] first reported the intercalation of 5-Fu into LDHs in 2005 using the reconstruction method. The orientation of 5-Fu within the interlayer galleries of the LDH host can be varied by changing the aging treatment or the swelling agent. The basal spacings of the hybrids obtained at $60{ }^{\circ} \mathrm{C}$ and $70{ }^{\circ} \mathrm{C}$ were 1.06 and $0.8 \mathrm{~nm}$, respectively, corresponding to a monolayer vertical and horizontal orientation to the layer, respectively, of the incorporated 5-Fu, whilst the hybrids obtained in glycerol with a basal spacing $1.24 \mathrm{~nm}$ may have a bilayer arrangement of 5-Fu anions. Different release mechanisms of 5-Fu were observed at varied $\mathrm{pH}$ values: an ion-exchange process between the 5-Fu anion pillared in the lamellar host and phosphate anions occurred in a buffer solution at $\mathrm{pH} 7$ while ion-exchange and removal of the inorganic host due to the partial dissolution of the LDH host was observed at $\mathrm{pH} 4$.

Choy et al. [95] also reported 5-Fu intercalated LDHs in 2008 using the coprecipitation method and evaluated the drug efficiency of 5-Fu-LDH against several cancer cell lines such as human lung cancer, osteosarcoma, and hepatoma cells and compared the results with those for MTX-LDH. Both 5-Fu-LDH and MTX-LDH nanohybrids more effectively inhibited cancer cell proliferation than free 5-Fu and MTX, respectively, though the performance of 5-FU-LDH was poorer than that of MTX-LDH.

Wei et al. [96] studied the intercalation of an inclusion complex of 5-Fu and $\beta$-cyclodextrin

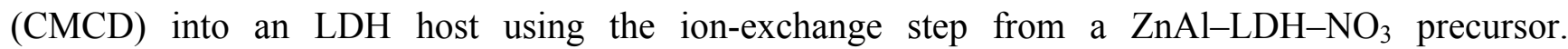
Spectroscopic studies showed that the structure of 5-Fu/CMCD inclusion complex is retained after 
immobilization in the $\mathrm{LDH}$ host. The release profiles of $5-\mathrm{Fu} / \mathrm{CMCD}$ in phosphate-citrate buffer (pH 4.8 and 7.2) at $37^{\circ} \mathrm{C}$ (Figure 15) indicated that a faster release and higher release amount of 5-Fu were observed at $\mathrm{pH} 7.2$ than in the acidic medium ( $\mathrm{pH} 4.8$ ). Inclusion of 5-Fu in the CMCD cavity prior to intercalation into LDH host prolongs the drug release time compared to the material obtained by direct intercalation of 5-Fu into the same $\mathrm{LDH}$. The release of 5-Fu from drug/CMCD-LDH composite follows the Korsmeyer-Peppas equation very well at varied $\mathrm{pH}$ values. The rate determining step for release of $5-\mathrm{Fu}$ from the 5-Fu/CMCD-LDH composite may be one of the following steps, depending on the conditions: (1) dissolution of LDH particles; (2) ion-exchange reaction between the inclusion complex 5-Fu/CMCD and citrate anions in the buffer solution; and (3) release of 5-FU from CMCD.

Figure 15. Release profiles of 5-Fu from 5-Fu/CMCD-LDH composite in phosphate-citrate buffer solution at different $\mathrm{pH}$ values. Reprinted with permission from [96] (Copyright 2010 American Chemical Society).

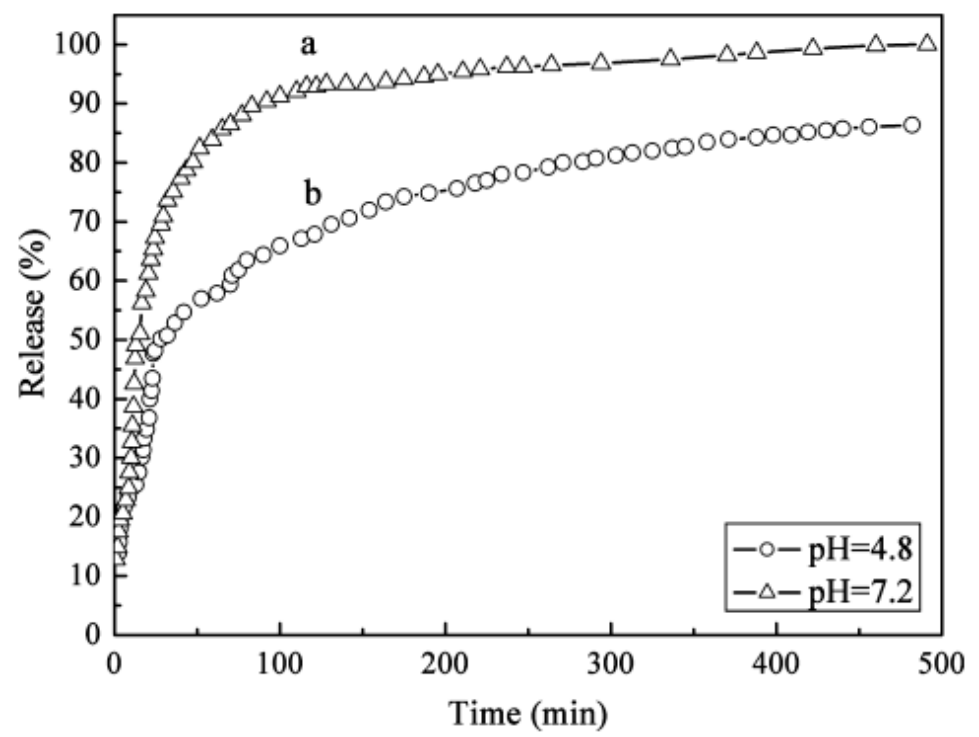

$\mathrm{Xu}$ et al. [97] reported another multifunctional nanovehicle for tumor optical imaging and therapy using $\mathrm{Y}_{2} \mathrm{O}_{3}: \mathrm{Er}^{3+}, \mathrm{Yb}^{3+}$ nanoparticles as near infrared fluorescent nanophosphors and MgAl-LDH-5-Fu nanosheets as drug nanovehicles. The hierarchically structured MgAl-LDH-5-Fu nanosheets were deposited on the surface of $\mathrm{Y}_{2} \mathrm{O}_{3}: \mathrm{Er}^{3+}, \mathrm{Yb}^{3+} @ \mathrm{SiO}_{2}$ (via a urea assisted homogenous precipitation route) by a simple precipitation step followed hydrothermal treatment. The surface of the nanospheres consists of self-assembled 5-Fu-LDH layers with individual 5-Fu-LDH nanoplatelets standing vertically to form an open structure, with the thickness of the 5-Fu-LDH nanoplatelets being around $70-100 \mathrm{~nm}$. The nanovehicle exhibits strong infrared upconversion fluorescence under excitation by a $980 \mathrm{~nm}$ laser which allows its extent of uptake by cancer cells to be monitored. The nanovehicle has a better anti-cancer efficiency than free 5-Fu attributed to its positively charged surfaces which results in a favorable interaction with the negatively charged cell membranes.

Doxifluridine (DFUR) is another important and frequently used anticancer drug with more effective and less toxic properties than 5-Fu. However, its application in clinical treatment is still limited by the side effects of oral administration such as diarrhea, nausea, and mucositis. Zhang et al. [17] fabricated 
a series of DUFR intercalated $\mathrm{MgAl}-\mathrm{LDH}$ microhybrids with varied $\mathrm{Mg} / \mathrm{Al}$ molar ratios (denoted as $r$ ) ranging from 1.7 to 2.9 and $\mathrm{pH}$ values (denoted as $p$ ) during aging step ranging from 7.2 to 10 via the reconstruction method (Figure 16).

Figure 16. Resonance structure of doxifluridine (DFUR) and the synthetic strategy for DFUR-LDH hybrids. Modified with permission from [17] (Copyright 2010 Elsevier).
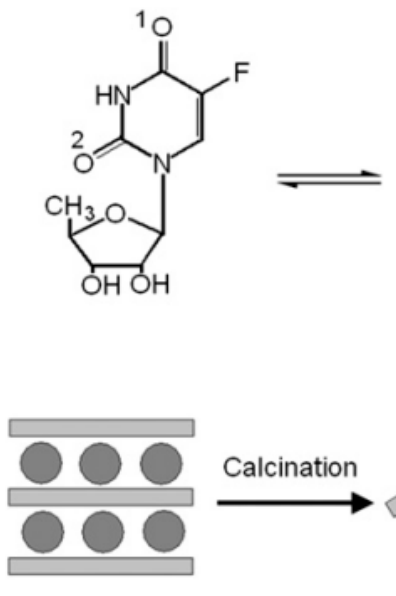

$\mathrm{CO}_{3}-\mathrm{LDH}$

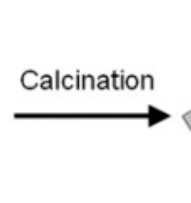

(1)

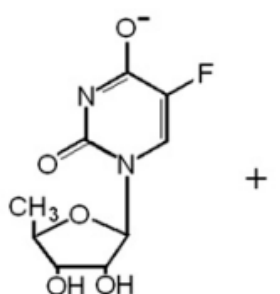

(a)

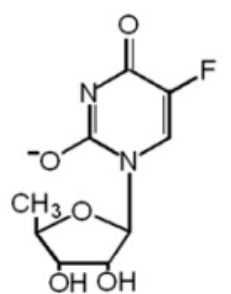

(b)

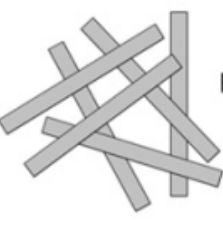

LDO

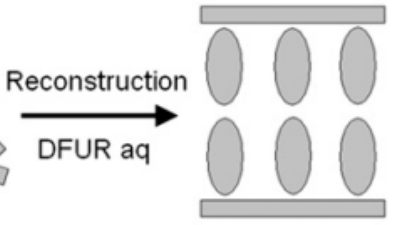

DFUR-LDH

The arrangement of DFUR within the interlayer galleries of the LDH was found to depend on both $\mathrm{Mg} / \mathrm{Al}$ ratios and the reaction $\mathrm{pH}$ values as a result of the different arrangements of the guest anions within the interlayer galleries, i.e., with a bilayer interlayer arrangement for DFUR-LDH $1.7 p 7.2$ and a more compact arrangement for DFUR-LDHr2.0p9.5. The particle morphologies also varied with both $\mathrm{Mg} / \mathrm{Al}$ ratios and reaction $\mathrm{pH}$ values. For example, DFUR-LDHr1.7p7.2 consists of interconnected spheres with particle size of 500-700 nm and a worm-like morphology, which can be identified as the embryo of a rosette-like morphology, whilst DFUR-LDHr2.0p9.5 has much smaller irregular plate-like particles with observable breaks or holes (Figure 17(Left)).

The in vitro release profiles of DFUR from different DFUR-LDH microhybrids (Figure 17(Right)) showed that DFUR-LDHr2.0p9.5 gives a much faster release rate than DFUR-LDHr1.7p7.2, probably due to the discontinuous morphology and the much smaller particle size of the former. On the other hand, DFUR-LDHr2.1p7.2 and DFUR-LDHr2.9p7.2 present much faster release rates than DFUR-LDHr 1.7p 7.2, being attributable to their lower layer charge densities and poorer crystallinity. The release data fitted well with Bhaskar and modified Freundlich models, demonstrating a heterogeneous particle diffusion mechanism of DFUR from the DFUR-LDH microhybrids. Further proper modification by Eudragit ${ }^{\circledR}$ L 100, the DFUR-LDH $r 1.7 p 7.2 / \mathrm{L} 100$ presents a readily controllable release behavior relied on the variation of the release medium $\mathrm{pH}$ values. 
Figure 17. (Left) SEM images of DFUR-LDHr1.7p7.2 (A,B) and DFUR-LDHr2.0p9.5 (C,D); (Right) Release profiles of DFUR-LDHrip7.2 $(i=1.7,2.1,2.9)$ and DFUR-LDHr2.0p9.5. Modified with permission from [17] (Copyright 2010 Elsevier).
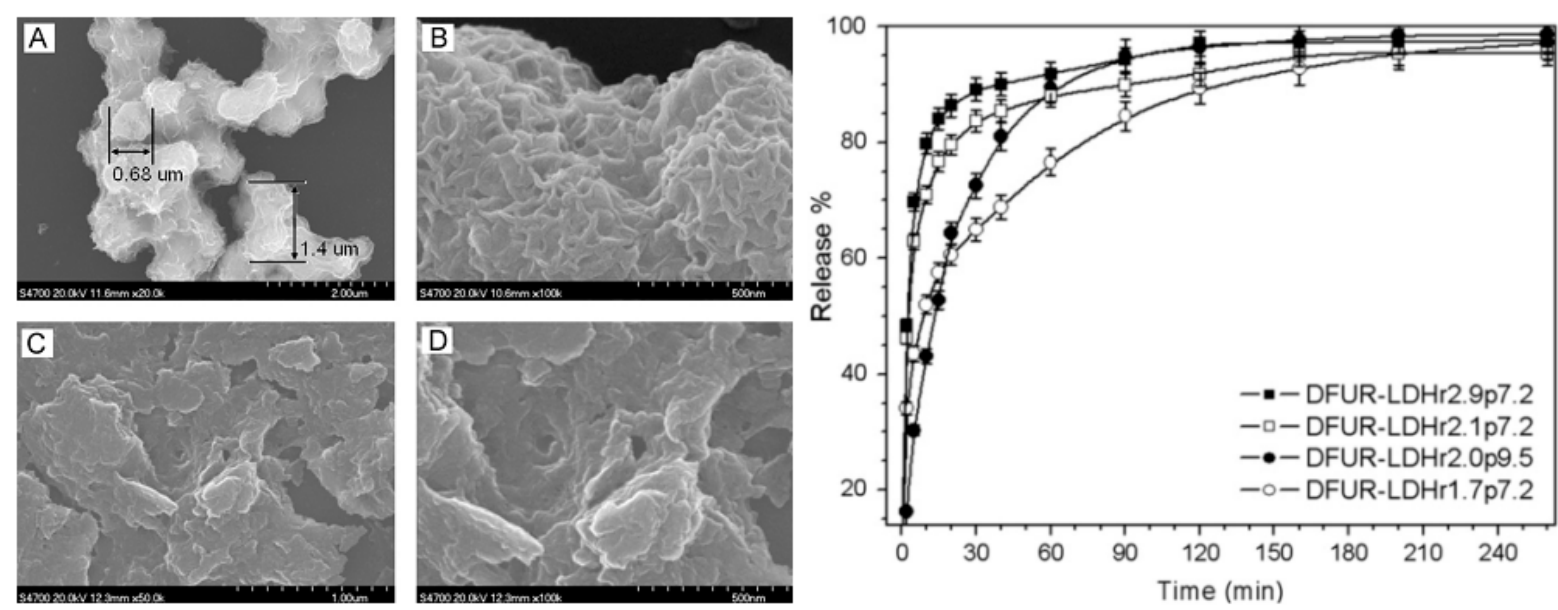

Some forms of active drugs are only slightly soluble in water, leading to poor dispersions in physiological solutions as well as difficulties in efficient dose delivery. In an attempt to overcome this problem, Giannelis et al. [98] first incorporated the non-ionic, poorly water-soluble camptothecin (CPT) into micelles derived from negatively charged surfactants, and then encapsulated in $\mathrm{MgAl}-\mathrm{LDH}$ particles by an ion-exchange step. The LDH crystals have a typical hexagonal shape with dimensions below $500 \mathrm{~nm}$ in two directions with the third dimension corresponding to the stacked inorganic sheets approximately $10 \mathrm{~nm}$. CPT was rapidly released from the resulting nanobiohybrids with complete release within $10 \mathrm{~min}$ at both $\mathrm{pH} 4.8$ and 7.2. When the nanobiohybrid containing the CPT was administered to Glioma cells in vitro, their survival times were significantly lower compared to untreated cells, or to cells incubated with the surfactant, the pristine LDH, or water (the delivery medium).

Hou et al. [99] prepared CPT-LDHs by a simple reconstruction of calcined LDHs using an organic solvent-water mixed solvent medium to increase the solubility of CPT. The composite is composed of very thin crimpled platelet-like particles of 100-200 nm. The CPT molecules are arranged as monolayer with their long axis parallel to the LDH layers. The in vitro drug release from the composites is significantly lower than that from the corresponding physical mixture. Hou et al. [100] recently reported the intercalation of CPT derivative 10-hydroxycamptothecin (HCPT) into sebacate-intercalated SC-LDHs upon hydrophobic interaction between HCPT and the parallel alkyl chains of monolayer arranged interlayer sebacate molecules. The obtained SC-HCPT-LDH composite consists of many nanosheets with a diameter of 300-500 nm and a thickness of 30-40 nm. The release kinetic studies ( $\mathrm{pH}$ 7.2 PBS) (Figure 18) upon different kinetic models indicated that the pseudo-second-order model is a more satisfactory description for the HCPT release process from SC-HCPT-LDH nanocomposites, which is similar to the previous report for the CPT-LDH obtained by the reconstruction method [99]. 
Figure 18. Release profiles (a) for CPT from a CPT-LDH composite and the physical mixture at $\mathrm{pH} 4.8$ and $\mathrm{pH} 7.2$ ( $\mathbf{m}$ : composite, $\mathrm{pH} 4.8$; $\bullet$ : composite, $\mathrm{pH} 7.2 ; \boldsymbol{\Delta}$ : physical mixture, $\mathrm{pH} 4.8 ; \boldsymbol{\nabla}$ : physical mixture, $\mathrm{pH}$ 7.2) and linear regression curves of release data fitted with the pseudo-second-order kinetic model at $\mathrm{pH} 4.8$ (b1) and $\mathrm{pH} 7.2$ (b2) ( $t$ refers to release time, $X_{t}$ refers to percentage releases, $q_{t}$ refers to release amount at any time $(t)$ ). Modified with permission from [99] (Copyright 2010 Elsevier).
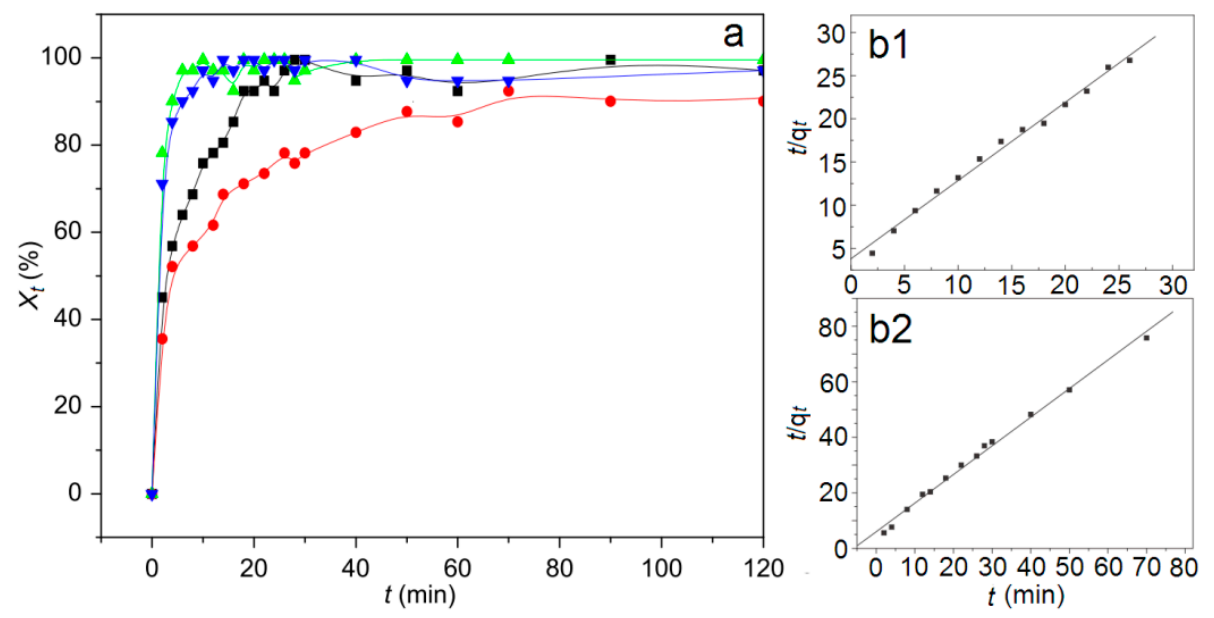

The intercalation of other anti-cancer drugs in LDHs has been less widely discussed. For instance, a drug delivery system composed of $\mathrm{Mg}_{2} \mathrm{Al}-\mathrm{NO}_{3}$ and $\mathrm{K}_{7}\left[\mathrm{PTi}_{2} \mathrm{~W}_{10} \mathrm{O}_{40}\right] \cdot 6 \mathrm{H}_{2} \mathrm{O}(\mathrm{PM}-19)$ was designed by Wang et al. [101]. The Keggin-type heteropolyoxotungstate a-nion PM-19 shows high anti-viral and anti-tumor activity, but also has high toxicity resulting in adverse effects on the human body. The gallery height of the obtained $\mathrm{Mg}_{2} \mathrm{Al}-\mathrm{PM}-19$ is $0.99 \pm 0.01 \mathrm{~nm}$, in line with the spherical diameter of PM-19 anion. This material shows a non-uniform, irregularly agglomerated, compact, and non-porous plate-like structure. The observed rapid release rate and 100\% release of PM-19 from the LDH composite after $60 \mathrm{~min}$ at $\mathrm{pH} 1$ can be attributed to the complete collapse of the LDH layered structure. At pH 4 and pH 7, the rapid release during the first 60 min was followed by a more sustained release of the drug; this is because when the large PM-19 anions are replaced by smaller phosphate anions from the buffer solution, a phase boundary between the internal zone containing the intercalated PM-19 and the external zone with the phosphate anions leads to a decrease in the rate of drug release.

The same group also reported a nanohybrid podophyllotoxin-LDH (PPT-LDH) by a two-step method [102] giving a material with particles of $80-90 \mathrm{~nm}$ and a zeta potential of $20.3 \mathrm{mV}$. The PPT-LDH particles show better anti-tumor efficiency than free PPT and are more readily taken up by Hela cells. PPT-LDH shows a long-term suppression effect on tumor growth, and enhances the apoptotic process of tumor cells. A pharmacokinetics study showed that PPT-LDH had a prolonged circulation time and an increased bioavailability compared with free PPT.

Shi et al. [103] developed a $\mathrm{Gd}^{3+}$ ions (magnetic resonance imaging (MRI) contrast agent) doped $\mathrm{LDH} / \mathrm{Au}$ (computed tomography (CT) contrast agent) nanocomposite as both a drug carrier and a diagnostic agent. The LDH-Gd/Au nanocomposite have a high surface area $\left(112.9 \mathrm{~m}^{2} \cdot \mathrm{g}^{-1}\right)$, and thus high loading (264 mg (DOX)/g carrier) of the non-anionic anti-cancer drug doxorubicin by hydrogen bonding interaction, and the loaded DOX shows an interesting $\mathrm{pH}$-responsive release, which is favorable for avoiding quick drug release in neutral blood system but promoting drug release at acidic 
tumor sites or within cells. Meanwhile, the nanocomposite has been found to be better CT and $\mathrm{T}_{1}$-weighted MRI contrast agents in vitro than commercial contrast agents, and effective $\mathrm{CT}$ and $\mathrm{T}_{1}$-weighted MRI contrast agents in vivo in reticuloendothelial systems such as liver and spleen and both CT and MR images present higher signal enhancements in spleen than in liver (Figure 19), suggesting that the synthesized disk-shaped LDH-Gd/Au nanocomposite is more easily enriched in spleen than in liver.

Figure 19. $T_{1}$-weighted MRI signal intensity and signal to noise ratio (SNR) of liver (a) and spleen (b) before (control) and after intravenous administration of $\mathrm{LDH}-\mathrm{Gd} / \mathrm{Au}$ nanocomposite/physiological saline at various intervals (dose: $3.1 \mathrm{mg}$ or $197.1 \mathrm{mmol} \cdot \mathrm{Gd} / \mathrm{kg}$ ). Reprinted with permission from [103] (Copyright 2013 Elsevier).

a

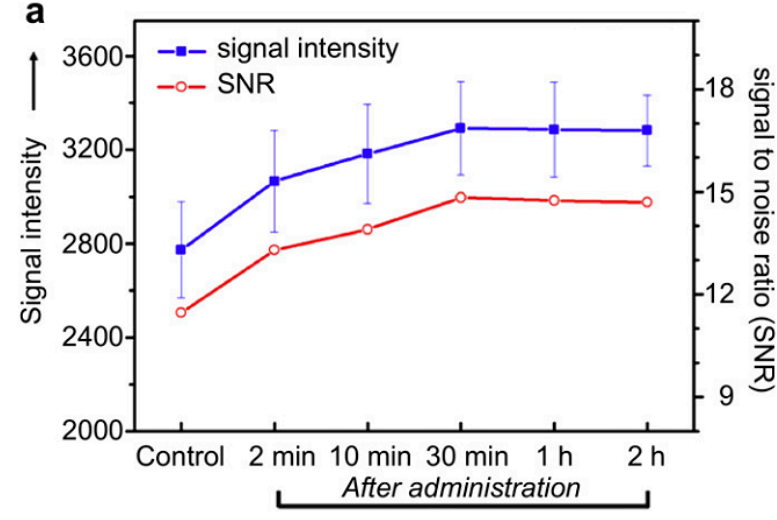

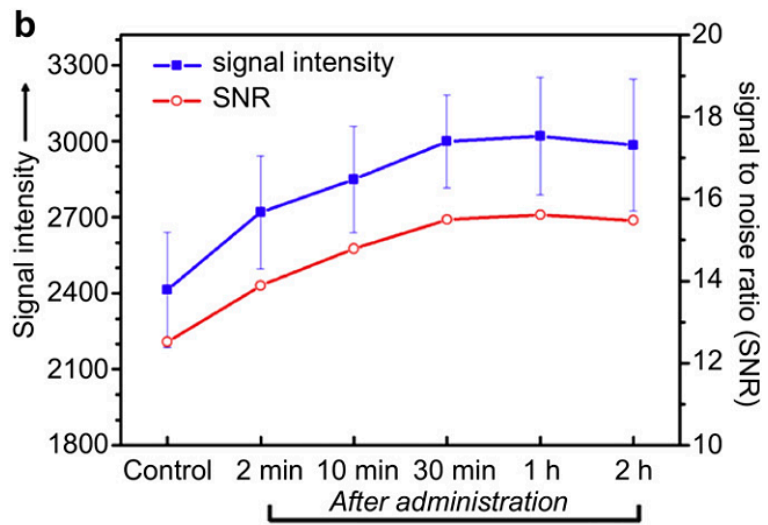

Based on above descriptions and discussions, it is concluded that the LDH nanoparticles can be considered as one of the ideal carriers for pharmaceutically active agents, and the obtained drug-LDH nanohybrid composites can be widely employed in future cardiovascular, anti-inflammatory and anti-cancer chemotherapies [104]. Besides the drugs mentioned above, some other kinds of drugs have also been co-assembled within LDH materials, including anti-histamine drugs [105], antioxidant drugs [106], peptide drugs [107], and amino acids [108]. Most of these drug-LDH composites show both good storage lifetimes because of the protection afforded by the LDH layers, and controlled release properties of the loaded drugs.

Table 1 summarizes all of the drug-LDH composites reviewed in this paper, indicating the intercalated drug, the chemical composition of the layers (metal cations), the preparation method, and a brief description of drug release conditions. 
Table 1. Brief summary of LDH-based DDS reviewed in this paper.

\begin{tabular}{|c|c|c|c|c|}
\hline Pharmaceutical guest & LDH host & Preparation & Drug Release & Ref. \\
\hline Gemfibrozil & $\mathrm{Li}, \mathrm{Al}$ & Ion-exchange & PBS (pH 4.0, 7.0) & {$[57]$} \\
\hline Captopril & $\mathrm{Mg}, \mathrm{Al}$ & Coprecipitation & PBS (pH 4.6, 7.4) & {$[58]$} \\
\hline Heparin & $\mathrm{Mg}, \mathrm{Al}$ & Coprecipitation & PBS (pH 7.4) & {$[59]$} \\
\hline Pravastatin & $\mathrm{Mg}, \mathrm{Al}$ & Coprecipitation & PBS (pH 7.5); $\mathrm{HCl}$ buffer ( $\mathrm{pH} 4.5$ ); simulated intestinal body fluids ( $\mathrm{pH} 7.0$ ) & {$[60]$} \\
\hline Fluvastatin & $\mathrm{Mg}, \mathrm{Al}$ & Coprecipitation & PBS (pH 7.5); HCl buffer ( $\mathrm{pH} 4.5$ ); simulated intestinal body fluids ( $\mathrm{pH} 7.0$ ) & {$[60]$} \\
\hline Bezafibrate & $\mathrm{Mg}, \mathrm{Al}$ & Coprecipitation & Simulated stomach sol. ( $\mathrm{pH}$ 2.0); Simulated duodenum sol. ( $\mathrm{pH}$ 6.0); Simulated intestine sol. ( $\mathrm{pH}$ 8.0) & {$[61]$} \\
\hline Clofibric acid & $\mathrm{Mg}, \mathrm{Al}$ & Coprecipitation & Simulated stomach sol. (pH 2.0); Simulated duodenum sol. (pH 6.0); Simulated intestine sol. (pH 8.0) & {$[61]$} \\
\hline Ibuprofen & $\mathrm{Mg}, \mathrm{Al}$ & Ion-exchange & PBS (pH 7.5) & {$[63]$} \\
\hline Ibuprofen & $\mathrm{Mg}, \mathrm{Al}$ & Coprecipitation & $\mathrm{HCl}$ aqueous solution & {$[64]$} \\
\hline Ibuprofen & $\mathrm{Mg}, \mathrm{Al}$ & Ion-exchange & $\mathrm{HCl}$ aqueous solution & {$[64]$} \\
\hline Ibuprofen & $\mathrm{Mg}, \mathrm{Al}$ & Reconstruction & $\mathrm{HCl}$ aqueous solution & {$[64]$} \\
\hline $\mathrm{Cu}$ (II)-ibuprofen & $\mathrm{Mg}, \mathrm{Al}$ & Adsorption & $\mathrm{HCl}$ aqueous solution & {$[64]$} \\
\hline Ibuprofen & $\mathrm{Mg}, \mathrm{Al}$ & Ion-exchange & - & {$[65]$} \\
\hline Ibuprofen & $\mathrm{Mg}, \mathrm{Al}$ & Coprecipitation & PBS (pH 7.0) & {$[66]$} \\
\hline Ibuprofen & $\mathrm{Mg}, \mathrm{Al}$ & Reconstruction & PBS (pH 7.0) & {$[42]$} \\
\hline Ibuprofen & $\mathrm{Mg}, \mathrm{Al}$ & Hydrothermal & PBS (pH 7.45) & [43] \\
\hline Ibuprofen & $\mathrm{Zn}, \mathrm{Al}$ & Ion-exchange & PBS (pH 7.4) & {$[67]$} \\
\hline Naproxen & $\mathrm{Mg}, \mathrm{Al}$ & Ion-exchange & - & {$[68]$} \\
\hline Naproxen & $\mathrm{Mg}, \mathrm{Al}$ & Coprecipitation & PBS (pH 7.4) & {$[69,71]$} \\
\hline Naproxen & $\mathrm{Mg}, \mathrm{Al}$ & Reconstruction & - & [69] \\
\hline Naproxen & $\mathrm{Mg}, \mathrm{Fe}, \mathrm{Al}$ & Coprecipitation & PBS (pH 7.5) & {$[70]$} \\
\hline Naproxen & $\mathrm{Mg}, \mathrm{Fe}, \mathrm{Al}$ & Ion-exchange & PBS (pH 7.5) & {$[70]$} \\
\hline Naproxen & $\mathrm{Zn}, \mathrm{Al}$ & Ion-exchange & PBS (pH 6.86) & {$[72]$} \\
\hline Diclofenac & $\mathrm{Mg}, \mathrm{Al}$ & Ion-exchange & PBS (pH 6.8, 7.5) & {$[65,73,75]$} \\
\hline Diclofenac & $\mathrm{Zn}, \mathrm{Al}$ & Ion-exchange & Simulated intestinal fluid (pH: $7.5 \pm 0.1)$; PBS (pH: $7.0 \pm 0.1)$ & {$[74,75]$} \\
\hline Diclofenac & $\mathrm{Zn}, \mathrm{Mg}, \mathrm{Al}$ & Ion-exchange & - & {$[75]$} \\
\hline Diclofenac & $\mathrm{Zn}, \mathrm{Al}$ & Coprecipitation & Physiological serum (pH 5.5) & {$[76]$} \\
\hline Ketoprofen & $\mathrm{Mg}, \mathrm{Zn}, \mathrm{Al}$ & Ion-exchange & - & {$[75]$} \\
\hline
\end{tabular}


Table 1. Cont.

\begin{tabular}{|c|c|c|c|c|}
\hline Pharmaceutical guest & LDH host & Preparation & Drug Release & Ref. \\
\hline Ketoprofen & $\mathrm{Zn}, \mathrm{Al}$ & Coprecipitation & Physiological serum (pH 5.5) & {$[76]$} \\
\hline Chloramphenicol & $\mathrm{Mg}, \mathrm{Zn}, \mathrm{Al}$ & Ion-exchange & - & {$[75]$} \\
\hline Chloramphenicol & $\mathrm{Zn}, \mathrm{Al}$ & Coprecipitation & Physiological serum (pH 5.5) & {$[76]$} \\
\hline Fenbufen & $\mathrm{Mg}, \mathrm{Al}$ & Ion-exchange & PBS (pH 7.8) & {$[77]$} \\
\hline Fenbufen & $\mathrm{Li}, \mathrm{Al}$ & Ion-exchange & PBS (pH 7.8) & [77] \\
\hline Fenbufen & $\mathrm{Mg}, \mathrm{Al}$ & Coprecipitation & PBS (pH 6.8, 7.4, 7.8) & {$[78]$} \\
\hline Fenbufen & $\mathrm{Mg}, \mathrm{Al}, \mathrm{Fe}$ & Coprecipitation & PBS (pH 7.5) & {$[79]$} \\
\hline Fenbufen & $\mathrm{Mg}, \mathrm{Al}, \mathrm{Fe}$ & Ion-exchange & PBS (pH 7.5) & {$[79]$} \\
\hline Fenbufen & $\mathrm{Mg}, \mathrm{Al}, \mathrm{Fe}$ & Reconstruction & PBS (pH 7.5) & {$[79]$} \\
\hline Flurbiprofen & $\mathrm{Mg}, \mathrm{Al}$ & Ion-exchange & PBS (pH 7.4) & {$[80]$} \\
\hline Flurbiprofen & $\mathrm{Zn}, \mathrm{Al}$ & Coprecipitation & PBS (pH 7.4) & {$[81]$} \\
\hline Flurbiprofen & $\mathrm{Mg}, \mathrm{Al}$ & Coprecipitation & - & {$[69]$} \\
\hline Flurbiprofen & $\mathrm{Mg}, \mathrm{Al}$ & Reconstruction & - & {$[69]$} \\
\hline Indomethacin & $\mathrm{Mg}, \mathrm{Al}$ & Coprecipitation & Swiss mice in vivo & {$[82]$} \\
\hline Indomethacin & $\mathrm{Mg}, \mathrm{Al}$ & Reconstruction & Swiss mice in vivo & {$[82]$} \\
\hline Indomethacin & $\mathrm{Mg}, \mathrm{Al}$ & Ion-exchange & - & {$[65]$} \\
\hline Mefenamic acid & $\mathrm{Mg}, \mathrm{Fe}, \mathrm{Al}$ & Coprecipitation & Tris buffer (tris-hydroxymethyl-aminomethane $+\mathrm{H}_{3} \mathrm{PO}_{4}+$ lauryl sulphate, $\mathrm{pH} 9$ ) & {$[70]$} \\
\hline Mefenamic acid & $\mathrm{Mg}, \mathrm{Fe}, \mathrm{Al}$ & Ion-exchange & Tris buffer (tris-hydroxymethyl-aminomethane $+\mathrm{H}_{3} \mathrm{PO}_{4}+$ lauryl sulphate, $\mathrm{pH} 9$ ) & {$[70]$} \\
\hline Mefenamic acid & $\mathrm{Mg}, \mathrm{Al}$ & Coprecipitation & - & {$[83]$} \\
\hline Mefenamic acid & $\mathrm{Mg}, \mathrm{Al}$ & Ion-exchange & - & {$[83]$} \\
\hline Mefenamic acid & $\mathrm{Mg}, \mathrm{Al}$ & Reconstruction & - & {$[83]$} \\
\hline Meclofenamic acid & $\mathrm{Mg}, \mathrm{Fe}, \mathrm{Al}$ & Coprecipitation & PBS (pH 7.4) & {$[70]$} \\
\hline Meclofenamic acid & $\mathrm{Mg}, \mathrm{Fe}, \mathrm{Al}$ & Ion-exchange & PBS (pH 7.4) & {$[70]$} \\
\hline Meclofenamic acid & $\mathrm{Mg}, \mathrm{Al}$ & Coprecipitation & - & {$[83]$} \\
\hline Meclofenamic acid & $\mathrm{Mg}, \mathrm{Al}$ & Ion-exchange & - & {$[83]$} \\
\hline Meclofenamic acid & $\mathrm{Mg}, \mathrm{Al}$ & Reconstruction & - & {$[83]$} \\
\hline 5-Aminosalicylate & $\mathrm{Zn}, \mathrm{Al}$ & Coprecipitation & - & {$[30]$} \\
\hline 5-Aminosalicylate & $\mathrm{Zn}, \mathrm{Al}$ & Ion-exchange & - & {$[30]$} \\
\hline Dexamethasone & $\mathrm{Mg}, \mathrm{Al}$ & Coprecipitation & PBS (pH 7.4) & {$[84]$} \\
\hline Folinic acid & $\mathrm{Mg}, \mathrm{Al}$ & Ion-exchange & Human tendinous fibroblast cell line and human osteosarcoma cell line (SaOS-2) in vitro & {$[48]$} \\
\hline
\end{tabular}


Table 1. Cont

\begin{tabular}{|c|c|c|c|c|}
\hline Pharmaceutical guest & LDH host & Preparation & Drug Release & Ref. \\
\hline Methotrexate & $\mathrm{Mg}, \mathrm{Al}$ & Ion-exchange & Human tendinous fibroblast cell line and human osteosarcoma cell line (SaOS-2) in vitro & {$[48]$} \\
\hline Methotrexate & $\mathrm{Mg}, \mathrm{Al}$ & Coprecipitation & MNNG/HOS cells in vitro & {$[50]$} \\
\hline Methotrexate & $\mathrm{Mg}, \mathrm{Al}$ & Coprecipitation & Human osteosarcoma cell lines; Saos-2 \& MG-63 & {$[86]$} \\
\hline Methotrexate & $\mathrm{Mg}, \mathrm{Al}$ & Coprecipitation & Deionized water; Hank's balanced salt solution; human breast adenocarcinoma MCF-7 cells & {$[87]$} \\
\hline Methotrexate & $\mathrm{Mg}, \mathrm{Al}$ & Coprecipitation & Parental HOS and MTX-resistant HOS/Mtx cells & {$[88]$} \\
\hline Methotrexate & $\mathrm{Mg}, \mathrm{Al}$ & Ex situ ion-exchange & PBS (pH 7.4) & {$[89]$} \\
\hline Methotrexate & $\mathrm{Mg}, \mathrm{Al}$ & In situ coprecipitation & PBS (pH 7.4) & {$[89]$} \\
\hline Methotrexate & $\mathrm{Mg}, \mathrm{Al}$ & Ex situ coprecipitation & PBS (pH 7.4) & {$[89]$} \\
\hline Methotrexate & $\mathrm{Zn}, \mathrm{Al}$ & Ion-exchange & PBS (pH 7.4) & {$[90]$} \\
\hline Methotrexate & $\mathrm{Mg}, \mathrm{Al}$ & Ion-exchange & PBS (pH 7.4) & {$[91]$} \\
\hline Methotrexate & $\mathrm{Mg}, \mathrm{Al}$ & In situ ion-exchange & PBS (pH 7.4) & {$[92]$} \\
\hline Methotrexate & $\mathrm{Mg}, \mathrm{Al}$ & Coprecipitation & Human lung cancer; osteosarcoma; hepatoma cells & {$[95]$} \\
\hline 5-Fuorouracil & $\mathrm{Mg}, \mathrm{Al}$ & Reconstruction & PBS (pH 4, 7) & {$[94]$} \\
\hline 5-Fuorouracil & $\mathrm{Mg}, \mathrm{Al}$ & Coprecipitation & Human lung cancer; osteosarcoma; hepatoma cells & {$[95]$} \\
\hline 5-Fuorouracil & $\mathrm{Zn}, \mathrm{Al}$ & Ion-exchange & PBS (pH 4.8, 7.2) & {$[96]$} \\
\hline 5-Fuorouracil & $\mathrm{Mg}, \mathrm{Al}$ & Precipitation \& hydrothermal & MCF-7 cells & {$[97]$} \\
\hline Doxifluridine & $\mathrm{Mg}, \mathrm{Al}$ & Reconstruction & PBS (pH 7.45) & {$[17]$} \\
\hline Camptothecin & $\mathrm{Mg}, \mathrm{Al}$ & Ion-exchange & Glioma cells in vitro & {$[98]$} \\
\hline Camptothecin & $\mathrm{Mg}, \mathrm{Al}$ & Reconstruction & PBS (pH 4.8, 7.2) & [99] \\
\hline 10-Hydroxy-camptothecin & $\mathrm{Zn}, \mathrm{Al}$ & Hydrophobic interaction & $0.1 \mathrm{M}$ PBS (pH 7.2) & [100] \\
\hline $\mathrm{K}_{7}\left[\mathrm{PTi}_{2} \mathrm{~W}_{10} \mathrm{O}_{40}\right] \cdot 6 \mathrm{H}_{2} \mathrm{O}$ & $\mathrm{Mg}, \mathrm{Al}$ & Ion-exchange & PBS (pH 1, 4, 7) & [101] \\
\hline Podophyllotoxin & $\mathrm{Mg}, \mathrm{Al}$ & Ion-exchange & Healthy female nude mice & [101] \\
\hline Doxorubicin & $\mathrm{Mg}, \mathrm{Al}$ & Hydrogen bonding interaction & L929 cells and HeLa cells in vitro; Kunming mice & [103] \\
\hline Cetirizine & $\mathrm{Mg}, \mathrm{Al}$ & Ion-exchange & PBS (pH 4.8, 7.4) & [105] \\
\hline Cetirizine & $\mathrm{Zn}, \mathrm{Al}$ & Ion-exchange & PBS (pH 4.8, 7.4) & [105] \\
\hline Carnosine & $\mathrm{Mg}, \mathrm{Al}$ & Ion-exchange & PBS (pH 7.4) & [106] \\
\hline Gallic acid & $\mathrm{Mg}, \mathrm{Al}$ & Coprecipitation & PBS (pH 7.4) & [106] \\
\hline Glycy-L-Tyrosine & $\mathrm{Mg}, \mathrm{Al}$ & Solvent evaporation & PBS (pH 7.4) & [107] \\
\hline L-Tyrosine & $\mathrm{Mg}(\mathrm{Ni}, \mathrm{Zn}), \mathrm{Al}$ & Coprecipitation & - & [108] \\
\hline
\end{tabular}


As far as we can see, LDHs material has been successfully combined with pharmaceutical drug molecules and shows great potential for drug delivery. However, the crucial challenges in efficiently delivering drug guests by LDH carrier still exist. One is the inevitable or still not clearly revealed chemical and biological toxicity of these drug-LDH nanoparticles despite their generally lower level compared with other inorganic nanoparticles. Another one is the non-selectivity of the drug-LDH for the targeted sites, resulting in an aimless and less efficient delivery. The third one is the less precise control of particle size and size distribution which may limit the efficient transportation of drug-LDH in vivo considering the possible damage of tissue or the phagocytosis of phagocytic cells. All these issues may alternatively rely on the modification or functionalization of drug-LDH hybrid which can promote the biological affinity to organism, the recognition capability to lesions, and the ability of delivery in vivo.

For the most commonly studied cardiovascular drugs and anti-inflammatory drugs mentioned above, the aim of sustained and controlled release has already been achieved practically. However, for the same kinds of drugs like anti-cancer drugs which need special requirements of release process with precise control to targeted site, further studies are still needed. Hence, novel structures and synthetic strategies are continuously being proposed [40,109-111] to solve this problem.

The introduction of a third component such as magnetic materials greatly pushes the functionalization process forward. Magnetic nanoparticles exhibit unique properties such as superparamagnetism [112], remote manipulation, magnetic imaging, and hyperthermic effect [113]. The use of magnetic nanoparticles affords greater flexibility to adjust the release process to improve the availability of drug molecules to the targeting therapeutic sites, and magnetic nanoparticles hybridized with drug-LDHs [114-117] are becoming one class of novel hierarchically structured bio-nanohybrid materials showing great application potential, which will be reviewed in the future.

\section{Conclusions}

By taking advantage of their ease of synthesis, structural diversity and stability, numerous LDH-based drug carrier systems have been employed as drug delivery system (DDS) and shown potential practical applications for the controlled release of a variety of pharmaceutical active agents. Most published studies have focused on the investigation of drug-LDH interactions and the in vitro behavior of drug guests in depth. The therapeutic advantages of LDH-based drug carriers make this field of investigation a high-priority development area. Nevertheless, some challenging problems still remain, particularly in respect to the synthesis of hierarchical complex structures with multifunctionality and the targeting of high efficiency release in vivo, and further results in these areas are eagerly awaited.

\section{Acknowledgments}

This work was supported by the 973 Program (2011CBA00508) and the National Natural Science Foundation of China (21276015) and PCSIRT (IRT1205).

\section{Conflicts of Interest}

The authors declare no conflict of interest. 


\section{References}

1. Allen, T.M.; Cullis, P.R. Drug delivery system: Entering the mainstream. Science 2004, 303, $1818-1822$.

2. De, M.; Ghosh, P.S.; Rotello, V.M. Applications of nanoparticles in biology. Adv. Mater. 2008, 20, 4225-4241.

3. Bhattarai, N.; Gunn, J.; Zhang, M.Q. Chitosan-based hydrogels for controlled, localized drug delivery. Adv. Drug Deliv. Rev. 2010, 62, 83-99.

4. Rösler, A.; Vandermeulen, G.W.M.; Klok, H.-A. Advanced drug delivery devices via self-assembly of amphiphilic block copolymers. Adv. Drug Deliv. Rev. 2012, 64, 270-279.

5. Kataoka, K.; Harada, A.; Nagasaki, Y. Block copolymer micelles for drug delivery: Design, characterization and biological significance. Adv. Drug Deliver. Rev. 2012, 64, 37-48.

6. Qiu, Y.; Park, K. Environment-sensitive hydrogels for drug delivery. Adv. Drug Deliv. Rev. 2012, 64, 49-60.

7. Siepmann, J.; Peppas, N.A. Modeling of drug release from delivery systems based on hydroxypropyl methylcellulose (HPMC). Adv. Drug Deliv. Rev. 2012, 64, 163-174.

8. Alvarez-Lorenzo, C.; Blanco-Fernandez, B.; Puga, A.M.; Concheiro, A. Crosslinked ionic polysaccharides for stimuli-sensitive drug delivery. Adv. Drug Deliv. Rev. 2013, 65, 1148-1171.

9. Zhang, N.; Wardwell, P.R.; Bader, R.A. Polysaccharide-based micelles for drug delivery. Pharmaceutics 2013, 5, 329-352.

10. Lawrence, M.J.; Rees, G.D. Microemulsion-based media as novel drug delivery systems. Adv. Drug Deliv. Rev. 2012, 64, 175-193.

11. Yoo, J.-W.; Irvine, D.J.; Discher, D.E.; Mitragotri, S. Bio-inspired, bioengineered and biomimetic drug delivery carriers. Nat. Rev. Drug Discov. 2011, 10, 521-535.

12. Tang, F.Q.; Li, L.L.; Chen, D. Mesoporous silica nanoparticles: Synthesis, biocompatibility and drug delivery. Adv. Mater. 2012, 24, 1504-1534.

13. Yang, P.P.; Gai, S.L.; Lin, J. Functionalized mesoporous silica materials for controlled drug delivery. Chem. Soc. Rev. 2012, 41, 3679-3698.

14. Alexis, F.; Pridgen, E.M.; Langer, R.; Farokhzad, O.C. Nanoparticle technologies for cancer therapy. Handb. Exp. Pharmacol. 2010, 197, 55-86.

15. Wei, P.-R.; Cheng, S.-H.; Liao, W.-N.; Kao, K.-C.; Weng, F.-C.; Lee, C.-H. Synthesis of chitosan-coated near-infrared layered double hydroxide nanoparticles for in vivo optical imaging. J. Mater. Chem. 2012, 22, 5503-5513.

16. Ribeiro, L.N.M.; Alcântara, A.C.S.; Darder, M.; Aranda, P.; Araújo-Moreira, F.M.; Ruiz-Hitzky, E. Pectin-coated chitosan-LDH bionanocomposite beads as potential systems for colon-targeted drug delivery. Int. J. Pharm. 2014, 463, 1-9.

17. Pan, D.K.; Zhang, H.; Zhang, T.; Duan, X. A novel organic-inorganic microhybrids containing anticancer agent doxifluridine and layered double hydroxides: Structure and controlled release properties. Chem. Eng. Sci. 2010, 65, 3762-3771.

18. Aguzzi, C.; Cerezo, P.; Viseras, C.; Caramella, C. Use of clays as drug delivery systems: Possibilities and limitations. Appl. Clay Sci. 2007, 36, 22-36. 
19. Cavani, F.; Trifirò, F.; Vaccari, A. Hydrotalcite-type anionic clays: Preparation, properties and applications. Catal. Today 1991, 11, 173-301.

20. Khan, A.I.; O'Hare, D. Intercalation chemistry of layered double hydroxides: Recent developments and applications. J. Mater. Chem. 2002, 12, 3191-3198.

21. Evans, D.G.; Duan, X. Preparation of layered double hydroxides and their applications as additives in polymers, as precursors to magnetic materials and in biology and medicine. Chem. Commun. 2006, doi:10.1039/B510313B.

22. Williams, G.R.; O'Hare, D. Towards understanding, control and application of layered double hydroxide chemistry. J. Mater. Chem. 2006, 16, 3065-3074.

23. Wang, Q.; O'Hare, D. Recent advances in the synthesis and application of layered double hydroxide (LDH) nanosheets. Chem. Rev. 2012, 112, 4124-4155.

24. Xu, Z.P.; Stevenson, G.S.; Lu, C.Q.; Lu, G.Q.; Bartlett, P.F.; Gray, P.P. Stable suspension of layered double hydroxide nanoparticles in aqueous solution. J. Am. Chem. Soc. 2006, 128, 36-37.

25. Sideris, P.J.; Nielsen, U.G.; Gan, Z.H.; Grey, C.P. Mg/Al ordering in layered double hydroxides revealed by multinuclear NMR spectroscopy. Science 2008, 321, 113-117.

26. Centi, G.; Perathoner, S. Catalysis by layered materials: A review. Microporous Mesoporous Mater. 2008, 107, 3-15.

27. Del Hoyo, C. Layered double hydroxides and human health: An overview. Appl. Clay Sci. 2007, $36,103-121$.

28. Ladewig, K.; Xu, Z.P.; Lu, G.Q. Layered double hydroxide nanoparticles in gene and drug delivery. Expert Opin. Drug Deliv. 2009, 6, 907-922.

29. Goh, K.-H.; Lim, T.-T.; Dong, Z.L. Application of layered double hydroxides for removal of oxyanions: A review. Water Res. 2008, 42, 1343-1368.

30. Zou, K.; Zhang, H.; Duan, X. Studies on the formation of 5-aminosalicylate intercalated $\mathrm{Zn}-\mathrm{Al}$ layered double hydroxides as a function of $\mathrm{Zn} / \mathrm{Al}$ molar ratios and synthesis routes. Chem. Eng. Sci. 2007, 62, 2022-2031.

31. Leroux, F.; Besse, J.-P. Polymer interleaved layered double hydroxide: A new emerging class of nanocomposites. Chem. Mater. 2001, 13, 3507-3515.

32. Alcântara, A.C.S.; Aranda, P.; Darder, M.; Ruiz-Hitzky, E. Bionanocomposites based on alginate-zein/layered double hydroxide materials as drug delivery systems. J. Mater. Chem. 2010, 20, 9495-9504.

33. Miao, Y.-E.; Zhu, H.; Chen, D.; Wang, R.Y.; Tjiu, W.W.; Liu, T.X. Electrospun fibers of layered double hydroxide/biopolymer nanocomposites as effective drug delivery systems. Mater. Chem. Phys. 2012, 134, 623-630.

34. Chakraborti, M.; Jackson, J.K.; Plackett, D.; Brunette, D.M.; Burt, H.M. Drug intercalation in layered double hydroxide clay: Application in the development of a nanocomposite film for guided tissue regeneration. Int. J. Pharm. 2011, 416, 305-313.

35. Bugatti, V.; Gorrasi, G.; Montanari, F.; Nocchetti, M.; Tammaro, L.; Vittoria, V. Modified layered double hydroxides in polycaprolactone as a tunable delivery system: In vitro release of antimicrobial benzoate derivatives. Appl. Clay Sci. 2011, 52, 34-40. 
36. Bao, H.F.; Yang, J.P.; Huang, Y.; Xu, Z.P.; Hao, N.; Wu, Z.X.; Lu, G.Q.; Zhao, D.Y. Synthesis of well-dispersed layered double hydroxide core@ordered mesoporous silica shell nanostructure (LDH@ $\left.\mathrm{mSiO}_{2}\right)$ and its application in drug delivery. Nanoscale 2011, 3, 4069-4073.

37. Liu, J.; Harrison, R.; Zhou, J.Z.; Liu, T.T.; Yu, C.Z.; Lu, G.Z.; Qiao, S.Z.; Xu, Z.P. Synthesis of nanorattles with layered double hydroxide core and mesoporous silica shell as delivery vehicles. J. Mater. Chem. 2011, 21, 10641-10644.

38. Zhang, H.; Zou, K.; Sun, H.; Duan, X. A magnetic organic-inorganic composite: Synthesis and characterization of magnetic 5-aminosalicylic acid intercalated layered double hydroxides. J. Solid State Chem. 2005, 178, 3485-3493.

39. Zhou, L.L.; Yuan, J.Y.; Wei, Y. Core-shell structural iron oxide hybrid nanoparticles: From controlled synthesis to biomedical applications. J. Mater. Chem. 2011, 21, 2823-2840.

40. Pan, D.K.; Zhang, H.; Fan, T.; Chen, J.G.; Duan, X. Nearly monodispersed core-shell structural $\mathrm{Fe}_{3} \mathrm{O}_{4} @$ DFUR-LDH submicro particles for magnetically controlled drug delivery and release. Chem. Commun. 2011, 47, 908-910.

41. Oh, M.-J.; Biswick, T.T.; Choy, J.-H. Layered nanomaterials for green materials. J. Mater. Chem. 2009, 19, 2553-2563.

42. Gunawan, P.; Xu, R. Direct assembly of anisotropic layered double hydroxide (LDH) nanocrystals on spherical template for fabrication of drug-LDH hollow nanospheres. Chem. Mater. 2009, 21, 781-783.

43. Huang, W.; Zhang, H.; Pan, D.K. Study on the release behavior and mechanism by monitoring the morphology changes of the large-sized drug-LDH nanohybrids. AIChE J. 2011, 57, 1936-1946.

44. Tarnawski, A.S.; Tomikawa, M.; Ohta, M.; Sarfeh, I.J. Antacid talcid activates in gastric mucosa genes encoding for EGF and its receptor. The molecular basis for its ulcer healing action. J. Physiol. Paris 2000, 94, 93-98.

45. Khan, A.I.; Ragavan, A.; Fong, B.; Markland, C.; O’Brien, M.; Dunbar, T.G.; Williams, G.R.; O'Hare, D. Recent developments in the use of layered double hydroxides as host materials for the storage and triggered release of functional anions. Ind. Eng. Chem. Res. 2009, 48, 10196-10205.

46. Choi, S.-J.; Oh, J.-M.; Choy, J.-H. Biocompatible nanoparticles intercalated with anticancer drug for target delivery: Pharmacokinetic and biodistribution study. J. Nanosci. Nanotechnol. 2010, 10, 2913-2916.

47. Panyam, J.; Labhasetwar, V. Biodegradable nanoparticles for drug and gene delivery to cells and tissue. Adv. Drug Deliv. Rev. 2012, 64, 61-71.

48. Choy, J.-H.; Jung, J.-S.; Oh, J.-M.; Park, M.; Jeong, J.; Kang, Y.-K.; Han, O.-J. Layered double hydroxide as an efficient drug reservoir for folate derivatives. Biomaterials 2004, 25, 3059-3064.

49. Posati, T.; Bellezza, F.; Tarpani, L.; Perni, S.; Latterini, L.; Marsili, V.; Cipiciani, A. Selective internalization of ZnAl-HTlc nanoparticles in normal and tumor cells. A study of their potential use in cellular delivery. Appl. Clay Sci. 2012, 55, 62-69.

50. Oh, J.-M.; Choi, S.-J.; Kim, S.-T.; Choy, J.-H. Cellular uptake mechanism of an inorganic nanovehicle and its drug conjugates: Enhanced efficacy due to clathrin-mediated endocytosis. Bioconjug. Chem. 2006, 17, 1411-1417. 
51. Choi, S.-J.; Oh, J.-M.; Choy, J.-H. Human-related application and nanotoxicology of inorganic particles: Complementary aspects. J. Mater. Chem. 2008, 18, 615-620.

52. Choi, S.-J.; Oh, J.M.; Choy, J.-H. Toxicological effects of inorganic nanoparticles on human lung cancer A549 cells. J. Inorg. Biochem. 2009, 103, 463-471.

53. Choi, S.-J.; Choy, J.-H. Layered double hydroxide nanoparticles as target-specific delivery carriers: Uptake mechanism and toxicity. Nanomedicine 2011, 6, 803-814.

54. Nel, A.; Xia, T.; Mädler, L.; Li, N. Toxic potential of materials at the nanolevel. Science 2006, $311,622-627$.

55. Choi, S.-J.; Oh, J.-M.; Choy, J.-H. Safety aspect of inorganic layered nanoparticles: Size-dependency in vitro and in vivo. J. Nanosci. Nanotechnol. 2008, 8, 5297-5301.

56. Baek, M.; Kim, I.-S.; Yu, J.; Chung, H.E.; Choy, J.-H.; Choi, S.-J. Effect of different forms of anionic nanoclays on cytotoxicity. J. Nanosci. Nanotechnol. 2011, 11, 1803-1806.

57. Khan, A.I.; Lei, L.X.; Norquist, A.J.; O’Hare, D. Intercalation and controlled release of pharmaceutically active compounds from a layered double hydroxide. Chem. Commun. 2001, doi:10.1039/B106465G.

58. Zhang, H.; Zou, K.; Guo, S.H.; Duan, X. Nanostructural drug-inorganic clay composites: Structure, thermal property and in vitro release of captopril-intercalated $\mathrm{Mg}-\mathrm{Al}$-layered double hydroxides. J. Solid State Chem. 2006, 179, 1791-1800.

59. Gu, Z.; Thomas, A.C.; Xu, Z.P.; Campbell, J.H.; Lu, G.Q. In vitro sustained release of LMWH from MgAl-layered double hydroxide nanohybrids. Chem. Mater. 2008, 20, 3715-3722.

60. Panda, H.S.; Strivastava, R.; Bahadur, D. In vitro release kinetics and stability of anticardiovascular drugs-intercalated layered double hydroxide nanohybrids. J. Phys. Chem. B 2009, 113, 15090-15100.

61. Berber, M.R.; Hafez, I.H.; Minagawa, K.; Mon, T.; Tanaka, M. Nanocomposite formulation system of lipid-regulating drugs based on layered double hydroxide: Synthesis, characterization and drug release properties. Pharm. Res. 2010, 27, 2394-2401.

62. Rives, V.; del Arco, M.; Martín, C. Layered double hydroxides as drug carriers and for controlled release of non-steroidal antiinflammatory drugs (NSAIDs): A review. J. Control. Release 2013, 169, 28-39.

63. Ambrogi, V.; Fardella, G.; Grandolini, G.; Perioli, L. Intercalation compounds of hydrotalcite-like anionic clays with antiinflammatory agents-I. Intercalation and in vitro release of ibuprofen. Int. J. Pharm. 2001, 220, 23-32.

64. Gordijo, C.R.; Barbose, C.A.S.; da Costa Ferreira, A.M.; Constantino, V.R.L.; de Oliveira Silva, D. Immobilization of ibuprofen and copper-ibuprofen drugs on layered double hydroxides. J. Pharm. Sci. 2005, 94, 1135-1148.

65. Mohanambe, L.; Vasudevan, S. Anionic clays containing anti-inflammatory drug molecules: Comparison of molecular dynamics simulation and measurements. J. Phys. Chem. B 2005, 109, 15651-15658.

66. Gunawan, P.; Xu, R. Direct control of drug release behavior from layered double hydroxides through particle interactions. J. Pharm. Sci. 2008, 97, 4367-4378.

67. Deleon, V.H.; Nguyen, T.D.; Nar, M.; D’Souza, N.A.; Golden, T.D. Polymer nanocomposites for improved drug delivery efficiency. Mater. Chem. Phys. 2012, 132, 409-415. 
68. Wei, M.; Shi, S.X.; Wang, J.; Li, Y.; Duan, X. Studies on the intercalation of naproxen into layered double hydroxide and its thermal decomposition by in situ FT-IR and in situ HT-XRD. J. Solid State Chem. 2004, 177, 2534-2541.

69. Berber, M.R.; Minagawa, K.; Katoh, M.; Mori, T.; Tanaka, M. Nanocomposites of 2-arylpropionic acid drugs based on $\mathrm{Mg}-\mathrm{Al}$ layered double hydroxide for dissolution enhancement. Eur. J. Pharm. Sci. 2008, 35, 354-360.

70. Del Arco, M.; Fernández, A.; Martín, C.; Rives, V. Release studies of different NSAIDs encapsulated in Mg, Al, Fe-hydrotalcites. Appl. Clay Sci. 2009, 42, 538-544.

71. Carriazo, D.; del Arco, M.; Martín, C.; Ramos, C.; Rives, V. Influence of the inorganic matrix nature on the sustained release of naproxen. Microporous Mesoporous. Mater. 2010, 130, 229-238.

72. Hou, W.G.; Jin, Z.L. Synthesis and characterization of Naproxen intercalated Zn-Al layered double hydroxides. Colloid Polym. Sci. 2007, 285, 1449-1454.

73. Ambrogi, V.; Perioli, L.; Ricci, M.; Pulcini, L.; Nocchetti, M.; Giovagnoli, S.; Rossi, C. Eudragit $^{\circledR}$ and hydrotalcite-like anionic clay composite system for diclofenac colonic delivery. Microporous Mesoporous Mater. 2008, 115, 405-415.

74. Perioli, L.; Posati, T.; Nocchetti, M.; Bellezza, F.; Costantino, U.; Cipiciani, A. Intercalation and release of antiinflammatory drug diclofenac into nanosized $\mathrm{ZnAl}$ hydrotalcite-like compound. Appl. Clay Sci. 2011, 53, 374-378.

75. San Román, M.S.; Holgado, M.J.; Salinas, B.; Rives, V. Characterisation of diclofenac, ketoprofen or chloramphenicol succinate encapsulated in layered double hydroxides with the hydrotalcite-type structure. Appl. Clay Sci. 2012, 55, 158-163.

76. San Román, M.S.; Holgado, M.J.; Salinas, B.; Rives, V. Drug release from layered double hydroxides and from their polylactic acid (PLA) nanocomposites. Appl. Clay Sci. 2013, 71, 1-7.

77. Li, B.X.; He, J.; Evans, D.G.; Duan, X. Inorganic layered double hydroxides as a drug delivery system-Intercalation and in vitro release of fenbufen. Appl. Clay Sci. 2004, 27, 199-207.

78. Li, B.X.; He, J.; Evans, D.G.; Duan, X. Enteric-coated layered double hydroxides as a controlled release drug delivery system. Int. J. Pharm. 2004, 287, 89-95.

79. Del Arco, M.; Fernández, A.; Martín, C.; Rives, V. Solubility and release of fenbufen intercalated in $\mathrm{Mg}, \mathrm{Al}$ and $\mathrm{Mg}, \mathrm{Al}, \mathrm{Fe}$ layered double hydroxides (LDH): The effect of Eudragit ${ }^{\circledR}$ S 100 covering. J. Solid State Chem. 2010, 183, 3002-3009.

80. Perioli, L.; Ambrogi, V.; Nauta, L.; Nocchetti, M.; Rossi, C. Effects of hydrotalcite-like nanostructured compounds on biopharmaceutical properties and release of BCS class II drugs: The case of flurbiprofen. Appl. Clay Sci. 2011, 51, 407-413.

81. Kim, M.H.; Park, D.H.; Yang, J.H.; Choy, Y.B.; Choy, J.H. Drug-inorganic-polymer nanohybrid for transdermal delivery. Int. J. Pharm. 2013, 444, 120-127.

82. Del Arco, M.; Cebadera, E.; Gutiérrez, S.; Martín, C.; Montero, M.J.; Rives, V.; Rocha, J.; Sevilla, M.A. Mg, Al layered double hydroxides with intercalated indomethacin: Synthesis, characterization, and pharmacological study. J. Pharm. Sci. 2004, 93, 1649-1658.

83. Del Arco, M.; Fernández, A.; Martín, C.; Rives, V. Intercalation of mefenamic and meclofenamic acid anions in hydrotalcite-like matrixes. Appl. Clay Sci. 2007, 36, 133-140. 
84. Sahoo, P.K.; Panda, H.S.; Bahadur, D. Studies on the stability and kinetics of drug release of dexamethasone phosphate intercalated layered double hydroxides nanohybrids. Mater. Chem. Phys. 2013, 142, 106-112.

85. Riaz, U.; Ashraf, S.M. Double layered hydroxides as potential anti-cancer drug delivery agents. Mini Rev. Med. Chem. 2013, 13, 522-529.

86. Oh, J.-M.; Park, M.; Kim, S.-T.; Jung, J.-Y.; Kang, Y.-G.; Choy, J.-H. Efficient delivery of anticancer drug MTX through MTX-LDH nanohybrid system. J. Phys. Chem. Solids 2006, 67, 1024-1027.

87. Kim, J.Y.; Choi, S.-J.; Oh, J.-M.; Park, T.; Choy, J.-H. Anticancer drug-inorganic nanohybrid and its cellular interaction. J. Nanosci. Nanotechnol. 2007, 7, 3700-3705.

88. Choi, S.-J.; Choi, G.E.; Oh, J.-M.; Oh, Y.-J.; Park, M.-C.; Choy, J.-H. Anticancer drug encapsulated in inorganic lattice can overcome drug resistance. J. Mater. Chem. 2010, 20, 9463-9469.

89. Chakraborty, M.; Dasgupta, S.; Bose, P.; Misra, A.; Mandal, T.K.; Mitra, M.; Chakraborty, J.; Basu, D. Layered double hydroxide: Inorganic organic conjugate nanocarrier for methotrexate. J. Phys. Chem. Solids 2011, 72, 779-783.

90. Chakraborty, M.; Dasgupta, S.; Soundrapandian, C.; Chakraborty, J.; Ghosh, S.; Mitra, M.K.; Basu, D. Methotrexate intercalated ZnAl-layered double hydroxide. J. Solid State Chem. 2011, 184, 2439-2445.

91. Chakraborty, M.; Dasgupta, S.; Sengupta, S.; Chakraborty, J.; Ghosh, S.; Ghosh, J.; Mitra, M.K.; Mishra, A.; Mandal, T.K.; Basu, D. A facile synthetic strategy for Mg-Al layered double hydroxide material as nanocarrier for methotrexate. Ceram. Int. 2012, 38, 941-949.

92. Chakraborty, J.; Roychowdhury, S.; Sengupta, S.; Ghosh, S. Mg-Al layered double hydroxide-methotrexate nanohybrid drug delivery system: Evaluation of efficacy. Mater. Sci. Eng. C 2013, 33, 2168-2174.

93. Yan, L.; Chen, W.; Zhu, X.Y.; Huang, L.B.; Wang, Z.G.; Zhu, G.Y.; Roy, V.A.L.; Yu, K.N.; Chen, X.F. Folic acid conjugated self-assembled layered double hydroxide nanoparticles for high-efficacy-targeted drug delivery. Chem. Commun. 2013, 49, 10938-10940.

94. Wang, Z.L.; Wang, E.; Gao, L.; Xu, L. Synthesis and properties of $\mathrm{Mg}_{2} \mathrm{Al}$ layered double hydroxides containing 5-fluorouracil. J. Solid State Chem. 2005, 178, 736-741.

95. Choi, S.-J.; Oh, J.-M.; Choy, J.-H. Anticancer drug-layered hydroxide nanohybrids as potent cancer chemotherapy agents. J. Phys. Chem. Solids 2008, 69, 1528-1532.

96. Jin, L.; Liu, Q.; Sun, Z.Y.; Ni, X.Y.; Wei, M. Preparation of 5-fluorouracil/ $\beta$-cyclodextrin complex intercalated in layered double hydroxide and the controlled drug release properties. Ind. Eng. Chem. Res. 2010, 49, 11176-11181.

97. Chen, C.P.; Yee, L.K.; Gong, H.; Zhang, Y.; Xu, R. A facile synthesis of strong near infrared fluorescent layered double hydroxide nanovehicles with an anticancer drug for tumor optical imaging and therapy. Nanoscale 2013, 5, 4314-4320.

98. Tyner, K.M.; Schiffman, S.R.; Giannelis, E.P. Nanobiohybrids as delivery vehicles for camptothecin. J. Control. Release 2004, 95, 501-514.

99. Dong, L.; Li, Y.; Hou, W.G.; Liu, S.J. Synthesis and release behavior of composites of camptothecin and layered double hydroxide. J. Solid State Chem. 2010, 183, 1811-1816. 
100. Pang, X.J.; Ma, X.M.; Li, D.X.; Hou, W.G. Synthesis and characterization of 10-hydroxycamptothecin-sebacate-layered double hydroxide nanocomposites. Solid State Sci. 2013, 16, 71-75.

101. Wang, Z.L.; Wang, E.B.; Tian, S.Y.; Xiao, D.R. Intercalation of PM-19 into and in vitro release of anti-tumor drug from layered double hydroxide. Chem. Res. Chin. Univ. 2005, 21, 492-495.

102. Qin, L.L.; Xue, M.; Wang, W.R.; Zhu, R.R.; Wang, S.L.; Sun, J.; Zhang, R.; Sun, X.Y. The in vitro and in vivo anti-tumor effect of layered double hydroxides nanoparticles as delivery for podophyllotoxin. Int. J. Pharm. 2010, 388, 223-230.

103. Wang, L.J.; Xing, H.Y.; Zhang, S.J.; Ren, Q.G.; Pan, L.M.; Zhang, K.; Bu, W.B.; Zhang, X.P.; Zhou, L.P.; Peng, W.J.; et al. A Gd-doped Mg-Al-LDH/Au nanocomposite for CT/MRI bimodal imagings and simultaneous drug delivery. Biomaterials 2013, 34, 3390-3401.

104. Rives, V.; del Arco, M.; Martin, C. Intercalation of drugs in layered double hydroxides and their controlled release: A review. Appl. Clay Sci. 2014, 88-89, 239-269.

105. Hussein-Al-Ali, S.H.; Al-Qubaisi, M.; Hussein, M.Z.; Ismail, M.; Zainal, Z.; Hakim, M.Z. In vitro inhibition of histamine release behavior of cetirizine intercalated into $\mathrm{Zn} / \mathrm{Al}$ - and Mg/Al-layered double hydroxides. Int. J. Mol. Sci. 2012, 13, 5899-5916.

106. Kong, X.G.; Jin, L.; Wei, M.; Duan, X. Antioxidant drugs intercalated into layered double hydroxide: Structure and in vitro release. Appl. Clay Sci. 2010, 49, 324-329.

107. Kong, X.G.; Shi, S.X.; Han, J.B.; Zhu, F.J.; Wei, M.; Duan, X. Preparation of Glycy-L-tyrosine intercalated layered double hydroxide film and its in vitro release behavior. Chem. Eng. J. 2010, 157, 598-604.

108. Wei, M.; Yuan, Q.; Evans, D.G.; Wang, Z.Q.; Duan, X. Layered solid as a "molecular container" for pharmaceutical agent: L-Tyrosine-intercalated layered double hydroxides. J. Mater. Chem. 2005, 15, 1197-1203.

109. Ay, A.N.; Zümreoglu-Karan, B.; Temel, A.; Rives, V. Bioinorganic magnetic core-shell nanocomposites carrying antiarthritic agents: Intercalation of ibuprofen and glucuronic acid into Mg-Al-layered double hydroxides supported on magnesium ferrite. Inorg. Chem. 2009, 48, 8871-8877.

110. Wang, J.; Zhou, J.D.; Li, Z.S.; Song, Y.C.; Liu, Q.; Jiang, Z.H.; Zhang, M.L. Magnetic, luminescent Eu-doped $\mathrm{Mg}-\mathrm{Al}$ layered double hydroxide and its intercalation for ibuprofen. Chem. Eur. J. 2010, 16, 14404-14411.

111. Panda, H.S.; Bahadur, D. Study of the preparation, properties and kinetics of anion release in drug intercalated magnetic nanohybrids. Mater. Res. Bull. 2012, 47, 571-579.

112. Kim, J.-E.; Shin, J.-Y.; Cho, M.-H. Magnetic nanoparticles: An update of application for drug delivery and possible toxic effects. Arch. Toxicol. 2012, 86, 685-700.

113. Kumar, C.S.S.R.; Mohammad, F. Magnetic nanomaterials for hyperthermia-based therapy and controlled drug delivery. Adv. Drug Deliv. Rev. 2011, 63, 789-808.

114. Deng, H.; Li, X.L.; Peng, Q.; Wang, X.; Chen, J.P.; Li, Y.D. Monodisperse magnetic single-crystal ferrite microspheres. Angew. Chem. Int. Ed. 2005, 44, 2782-2785. 
115. Fan, T.; Pan, D.K.; Zhang, H. Study on formation mechanism by monitoring the morphology and structure evolution of nearly monodispersed $\mathrm{Fe}_{3} \mathrm{O}_{4}$ submicroparticles with controlled particle sizes. Ind. Eng. Chem. Res. 2011, 50, 9009-9018.

116. Zhang, H.; Pan, D.K.; Zou, K.; He, J.; Duan, X. A novel core-shell structured magnetic organic-inorganic nanohybrid involving drug-intercalated layered double hydroxides coated on a magnesium ferrite core for magnetically controlled drug release. J. Mater. Chem. 2009, 19, 3069-3077.

117. Zhang, H.; Pan, D.K.; Duan, X. Synthesis, characterization, and magnetically controlled release behavior of novel core-shell structural magnetic ibuprofen-intercalated LDH nanohybrids. J. Phys. Chem. C 2009, 113, 12140-12148.

(C) 2014 by the authors; licensee MDPI, Basel, Switzerland. This article is an open access article distributed under the terms and conditions of the Creative Commons Attribution license (http://creativecommons.org/licenses/by/3.0/). 